CEWP 20-08

\title{
Traffic Congestion, Transportation Policies, and the Performance of First Responders
}

\author{
Daniel A. Brent Louis-Philippe Béland \\ Pennsylvania State University Carleton University
}

May 2020

\section{CARLETON ECONOMICS WORKING PAPERS}

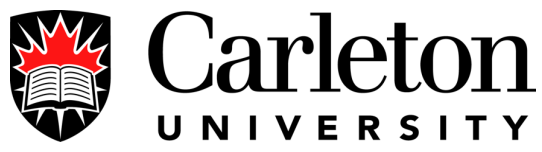

Department of Economics

1125 Colonel By Drive

Ottawa, Ontario, Canada

K1S 5B6 


\title{
TRAFFIC CONGESTION, TRANSPORTATION POLICIES, AND THE PERFORMANCE OF FIRST RESPONDERS
}

\author{
Daniel A. Brent \\ Pennsylvania State University
}

\author{
Louis-Philippe Beland \\ Carleton University
}

May 2020

\begin{abstract}
Traffic congestion is a growing problem in urbanizing economies that results in lost time, health problems from pollution, and contributes to the accumulation of greenhouse gas emissions. We examine a new external cost of traffic by estimating the relationship between traffic congestion and emergency response times. Matching traffic data at a fine spatial and temporal scale to incident report data from fire departments in California allows us to assign traffic immediately preceding an emergency. Our results show that traffic slows down fire trucks arriving at the scene of an emergency and increases the average monetary damages from fires. The effects are highly nonlinear; increases in response time are primarily due to traffic in the right tail of the traffic distribution. We document an additional externality of traffic congestion and highlight the negative effect of traffic on a critical public good.
\end{abstract}

JEL Classification: R41, R42, R48, H41, Q50

Keywords: Traffic, Public Goods, Externalities, Emergency Response Times 


\section{Introduction}

According to the National Emergency Number Association, over 240 million 911 calls are placed every year in the United-States. ${ }^{1}$ Rapidly responding to emergency calls requires an efficient network of first responders and dispatchers. The literature shows that response times for emergency medical services (EMS) are critical for a number of health outcomes including hospitalization, rehabilitation and survival following an accident, stroke or heart attack (Wilde, 2013; Emberson et al., 2014; Jena et al., 2017). Police response times have also been shown to affect crime clearance rates (Blanes i Vidal and Kirchmaier (2015)). Although

first responders are typically expeditious, one factor beyond their control that affects response times is traffic. This is a particularly pressing concern as increasing urbanization has led to more severe congestion in many cities.

In this paper, we examine the relationship between traffic and emergency response times by fire departments in California. In addition to responding to fires, we also have data on fire departments providing EMS and responding to other non-fire emergencies. We match traffic data at a fine spatial and temporal scale to incident report data from fire departments. The fire data consist of over 2.7 million incidents from 2008-2015 across California collected by the National Fire Incident Reporting System (NFIRS). The traffic data, collected from the California Department of Transportation, consists of roughly 21 billion observations from 25,000 stations at a five-minute interval resolution. The fine spatial and temporal scale of the traffic data allows us to merge traffic conditions immediately preceding the emergency event by zip code, date, and the time of day. We assign zip code level traffic conditions for every call to the fire department immediately prior to the fire department receiving the alarm. Our identifying assumption is that traffic in a given zip code, in a given month, on a given day of the week, within a given hour is uncorrelated with unobservables affecting emergency response times. This is plausibly exogenous since we use the traffic before the fire/accident occurs. Our final dataset, consists of 1.3 million incidents merged with zip code level traffic conditions.

We make three main contributions to the literature. First, we investigate a new external-

\footnotetext{
${ }^{1}$ For more details, see https://www.nena.org/?page=911Statistics
} 
ity of traffic by showing how traffic congestion affects an important public good; the ability of first responders to quickly arrive on the scene of emergencies. While the costs of traffic due to lost time and other externalities are well-documented, we believe it is important to focus on the effect of traffic on emergency response vehicles for two primary reasons. First, conventional economic measures of the time cost of traffic use value of time (VOT), which is often elicited from private drivers paying to increase speed (Small et al., 2005; Wolff, 2014; Gross and Brent, 2018). However, this ignores emergency response vehicles who do not pay tolls and likely have a vastly higher VOT than private drivers. Second, while conventional drivers are bound by the rules of the road, emergency response vehicles can force drivers to move out of the way, go through traffic lights, and use the road shoulders to avoid traffic. Therefore, it is uncertain whether traffic will slow down emergency response vehicles in the same manner as conventional drivers.

Our second contribution documents how a variety of policies affect both response times and the marginal effect of traffic on response times. This contributes to the growing literature evaluating the effectiveness of transportation policies on congestion and non-congestion traffic externalities such as pollution (Adler and van Ommeren, 2016; Beaudoin and Lin Lawell, 2018; Blackman et al., 2018; Hamilton and Wichman, 2018; Yang et al., 2018; Lalive et al., 2018; Li et al., 2019). Lastly, our third contribution estimates the economic damage imposed by slower response times due to traffic congestion. While most of the economic research on fires focuses on damages from wildfires (Donovan et al., 2007; Moeltner et al., 2013; Mueller et al., 2018; McCoy and Walsh, 2018), our work represents some of the first research on the economic damage of urban fires.

Our results show that traffic slows down fire trucks arriving at the scene of an emergency. This applies both to fire departments responding to fires and providing emergency medical services. Increasing the response time of first responders represents a newly documented externality to traffic, in addition to lost time, pollution, house prices, health, happiness and crime (e.g. Kahneman et al. (2004); Currie and Walker (2011); Anderson (2019), Knittel et al. (2016); Ossokina and Verweij (2015); Anderson et al. (2016) and Beland and Brent (2018)). The effects are highly nonlinear; increases in response times are primarily due to traffic in the right tail of the traffic distribution. For this reason, our main specification 
focuses on traffic above the 80th percentile. We also find suggestive evidence that fire departments are able to adapt to high traffic, and that unexpected traffic has a larger effect on response times.

Additionally, we investigate road congestion policies (high-occupancy vehicle lanes (HOV), toll roads, public transportation) that might mitigate this problem. We find that HOV lanes partially mitigate the marginal effects of traffic on response time. Lastly, we show evidence that traffic congestion increases the monetary damages of fires. In aggregate, the increased monetary damages from fires and emergency medical services due to traffic are approximately \$95-\$285 million per year in California, with the majority of costs coming from slower EMS response times. The costs from longer emergency response times are several orders of magnitude lower than other traffic externalities such the value of lost time and extra fuel, which were estimated to be over $\$ 40$ billion in Californian in 2017 (Schrank et al., 2019). These costs do not account for increased response times for ambulances or police, and therefore should be considered a lower bound for the costs of traffic on emergency response services. Additionally, we do not capture adapting expenditures by fire departments to cope with traffic congestion. Our results are robust to multiple specifications and robustness tests including metro-by-date fixed effects, different definitions of our traffic variable, and relaxing the temporal assumptions for assigning traffic to an emergency.

Our results highlight the importance of an efficient network of first responders, and the complementarity of certain types of public goods (Albouy et al., 2020). Since rapid response by first responders is critical, simply using the value of time, reliability and health effects from pollution will underestimate the costs of traffic congestion. The results also highlight the nonlinear impacts of traffic; similar to other research (Gross and Brent, 2018; Beland and Brent, 2018) the adverse impacts on response times are concentrated in the right tail of the traffic distribution. As urbanization shifts higher shares of the population to cities, it is important to understand the benefits of policies that reduce traffic congestion.

The rest of the paper is organized as follows: Section 2 discusses the related literature; Section 3 provides a description of the data and presents descriptive statistics; Section 4 presents the empirical strategy; Section 5 is devoted to the main results, heterogeneity of the impacts and a series of robustness checks; and Section 6 concludes with policy implications. 


\section{Related literature}

Our paper is related to the literature on traffic externalities, the importance of emergency response times, and road congestion policies. This article first fits into a broad literature investigating negative externalities to traffic. One of the largest externalities is the value of time and fuel expenditures associated with congestion, which is estimated to cost U.S. commuters $\$ 179$ billion in 2017 (Schrank et al. (2019)). Another important external cost of traffic documented in the literature is the effect of traffic on air quality and the subsequent health impacts. Currie and Walker (2011) show that traffic reductions due to the introduction of electronic toll collection, (E-ZPass) reduce vehicle emissions near highway toll plazas, which subsequently reduces premature births and low birth weight among mothers near a toll plaza. Pollution from traffic negatively affects children's contemporaneous health (Knittel et al., 2016) and has a long run effect on mortality within the elderly population (Anderson, 2019).

While the primary costs of traffic are mostly due to lost time and reliability, there is research using survey data linking traffic to negative mental health outcomes, including stress and aggression (Parkinson, 2001; Hennessy and Wiesenthal, 1999; Gee and Takeuchi, 2004; Gottholmseder et al., 2009; Roberts et al., 2011; Künn-Nelen, 2016; Anderson et al., 2016). Moreover, Beland and Brent (2018) find that extreme traffic events lead to an increase

in domestic violence in Los Angeles. There are several papers that investigate the role of traffic congestion in private decisions related to driving behavior (Burger and Kaffine, 2009; Couture et al., 2018). Ossokina and Verweij (2015) exploit a quasi-experiment that reduces traffic congestion on certain streets in the Netherlands and find that the decrease in traffic leads to an increase in housing prices. We contribute to the literature on the externalities of traffic by studying the negative effect of congestion on first responders' response times as an additional external cost of traffic.

This paper is also related to the literature on the importance of emergency response times. There are several medical papers that examine the effect of response times on health outcomes. The general consensus is that slower response times increase mortality for cardiac arrest (Larsen et al., 1993; Pell et al., 2001; Newgard et al., 2010). However, recent papers 
show that the lack of an association between response times and general trauma mortality may be due to endogeneity: first responders devote more resources (e.g. faster response times) to more severe trauma events that have higher mortality rates. Wilde (2013) uses distance from the hospital as an instrument to investigate the impact of response time on mortality and hospital utilization. The instrumental variable approach shows that increased emergency response times significantly increase mortality and the likelihood of being admitted to the hospital, while the OLS approach finds no effect. Jena et al. (2017) exploits marathons as a natural experiment that increases response times to investigate the effect on cardiac arrest outcomes. They find that patients who were admitted to marathon-affected hospitals with acute myocardial infarction or cardiac arrest had longer ambulance transport times before noon (4.4 minutes longer) and higher 30-day mortality than patients who were hospitalized on other days. The effect of response times is not limited to medical outcomes, as Blanes i Vidal and Kirchmaier (2015) show that police response times affect crime clearance rates. They find suggestive evidence in support of two mechanisms: a faster response time increases the likelihood of an immediate arrest and the likelihood that a suspect will be named by a victim or witness. We contribute to the literature by highlighting how traffic is an important input to emergency response times for fire departments using data at a fine spatial and temporal scale. Additionally, we contribute to the methodology of understanding the impact of response times on outcomes. Using time series variation in traffic as opposed to cross sectional variation in distance to hospitals (Wilde, 2013) relies on less stringent identification assumptions. Unlike Jena et al. (2017), we examine all extreme traffic, not just traffic from major events such as marathons.

Our paper is also related to the literature on road congestion policies that aim to reduce traffic externalities. According to Duranton and Turner (2011), building new road capacity is unlikely to reduce congestion in the long-run since the elasticity of travel demand with respect to capacity is roughly equal to one. Other research analyzes policies such as dynamic tolling (De Borger and Proost, 2013; Gross and Brent, 2018), road pricing (Gibson and Carnovale, 2015), HOV and HOT lanes (Konishi and Mun, 2010; Bento et al., 2014, 2013) and public transportation (Anderson, 2014; Adler and van Ommeren, 2016; Bauernschuster et al., 2017; Gendron-Carrier et al., 2018). Several studies find that increasing access to public transit 
reduces congestion and the pollution from driving in both Europe and China (Adler and van Ommeren, 2016; Beaudoin and Lin Lawell, 2018; Lalive et al., 2018; Yang et al., 2018; Li et al., 2019). The literature finds that these policies affect driving behaviors, decrease travel time, reduce congestion, and curtail pollution. We contribute to this literature by investigating if theses policies impact the marginal effect of traffic on first responders.

\section{Data sources, dataset creations \& descriptive statistics}

We collect data from several sources to construct our final estimation sample. The fire department incident data are collated from fire departments by the National Fire Incident Reporting System (NFIRS). NFIRS represents a uniform reporting standard for fire departments and emergency medical services (EMS), and represents the world's largest national database on fire incident reporting. The Federal Emergency Management Agency (FEMA) administers the NFIRS database. This database contains roughly 40 million incidents nationwide from 2008-2015. We focus on California due to the availability of high resolution traffic data; there are approximately 2.7 million incidents from 2008-2015 in California. There are eleven modules that contain detailed data on different elements of fire incidents. We use the basic module that includes data on the time the alarm was raised and the time the fire department arrived at the scene of the emergency. Our primary outcome variable is the response time in minutes, which is calculated by the arrival time minus the time the alarm was raised.

We focus on three types of calls: fires, emergency medical services, and other hazards. We exclude other types of incidents that do not require rapid arrival on the scene such as being locked out of a residence or animal control. Fire departments also report the dollar value of property and contents damaged due to the fire. We exclude all incidents coded as wildfires because these incidents likely have different dynamics for response times and monetary damages relative to most fires occurring in urban areas. We also remove all incidents that are coded as a response to a vehicle accident because the response times for these incidents may be correlated with traffic. ${ }^{2}$ Lastly, we drop 546 incidents that had

\footnotetext{
${ }^{2}$ The fact that we use traffic before the incident occurs alleviates this concern, but traffic congestion increases the probability of accidents and also generates more traffic. Therefore, to be conservative we drop these incidents.
} 
response times above five hours as these are likely data errors or not typical of traditional operations.

The traffic data are obtained from the California Department of Transportation through the Caltrans Performance Measurement System (PeMS). ${ }^{3}$ We access annual Station 5-minute datasets from 2008 to 2015 for approximately 25,000 monitoring stations over California. There are over 840,000 five-minute intervals for each of the 25,000 stations representing approximately 21 billion observations of traffic data. Since the fire incident data are geocoded at the zip code level, we aggregate the traffic data to the zip code level. We match the traffic and incident data at the location where the incident occurs because we do not have geospatial data on the origin of the emergency response vehicles. Emergency vehicles ultimately must cope with the traffic at the incident zip code, so we believe this is a valid modeling strategy. Additionally, in the Los Angeles County where we have geospatial data on fire station locations most zip codes have at least one fire station, so it is likely that the origin location is relatively close to the incident location. ${ }^{4}$

We create our traffic delay variable in four steps. First, we calculate the free-flow speeds in miles per hour (mph) for each monitoring station using speeds from midnight to 2 AM. ${ }^{5}$ Second, for each monitoring station we calculate the difference from the actual speed in a given 5-minute interval and the free-flow speed. Third, we generate monitoring station weights to account for the utilization of that monitoring station relative to other stations in that zip code. These weights are based on the sum of traffic occupancy for a given monitoring station divided by the sum of occupancy across all monitoring stations in the zip code. We re-calculate the weights each month to account for changing utilization patterns over time. Fourth, using the weights and the speed deviations we generate a weighted average of all monitoring stations in a zip code for each 5-minute interval. We refer to this variable as traffic delay. Section A of the Appendix provides formal descriptions of these steps. We also generate an unweighted version of this variable which calculates a simple average of all

\footnotetext{
${ }^{3}$ The data can be accessed via http://pems.dot.ca.gov/ A free account needs to be established.

${ }^{4}$ While we have geospatial data on fire stations locations we do not know the origin location of emergency vehicles at the incident level.

${ }^{5}$ We assume that traffic in the middle of the night approximates free flow although speeds may be faster during other times depending on the zip code.
} 
deviations in a zip code without the weights. The average delay across all times and zip codes is $5.4 \mathrm{mph}, 7.2 \mathrm{mph}$ during the morning commute, and $9.9 \mathrm{mph}$ during the evening commute. The interpretation of this delay variable is that the average speeds for zip codes in our sample is $5.4 \mathrm{mph}$ slower than free-flow speeds that occur from midnight to 2 AM. Table 1 presents the mean and standard deviation of response time and traffic delay for the full sample, each core based statistical area (CBSA), all urban areas combined, and non-urban areas. Response time is measured in minutes and delay is measured in miles per hour. Table 1 shows that traffic delay is small in non-urban areas, but the response time is slightly larger.

Table 1: Summary statistics of traffic and response times

\begin{tabular}{llrr}
\hline Variable & Sample & Mean & Std. Dev \\
\hline Delay & All & 5.4 & 8.5 \\
Delay & Urban & 6.0 & 8.9 \\
Delay & Non-urban & 2.6 & 4.9 \\
Delay & Los Angeles & 6.9 & 10.0 \\
Delay & Bay Area & 5.9 & 8.9 \\
Delay & San Diego & 5.1 & 8.1 \\
Delay & Sacramento & 4.9 & 6.9 \\
Response & All & 6.2 & 5.5 \\
Response & Urban & 6.1 & 5.2 \\
Response & Non-urban & 6.8 & 6.3 \\
Response & Los Angeles & 6.5 & 5.2 \\
Response & Bay Area & 5.8 & 4.5 \\
Response & San Diego & 6.4 & 4.6 \\
Response & Sacramento & 5.1 & 6.2 \\
\hline
\end{tabular}

Notes: The table presents mean and standard deviations for response times and traffic delays for several relevant sub-samples. Response time is measured in minutes and delay is measured in miles per hour. The Non-urban sample is the same as the Other CBSA - incidents that occur outside of one the primary metropolitan areas.

Monitoring stations only exist in a subset of zip codes so our final traffic dataset is comprised of a panel of over 570 million observations of 5-minute intervals from 725 zip codes over eight years. ${ }^{6}$ The monitoring stations are primarily on major roads in urban areas, although some non-urban areas are included. While the sample is not necessarily representative in this respect, we do capture the urban areas where traffic is most likely to be a major challenge for fire departments. Figure 1 presents a map of the study location and the roads considered. ${ }^{7}$

\footnotetext{
${ }^{6}$ The average monitoring stations per zip code in our sample is 41 . The minimum is 1 and the maximum is 215 .

${ }^{7}$ We contacted the fire departments to find out if traffic represented a challenge and whether they used the roads contained in the PemS data. Both the Los Angeles and San Francisco fire departments responded that traffic represented a challenge, that they use freeways, and that spillover traffic from freeways impacted response times. These correspondence are available upon request.
} 
Figure 1: Study location

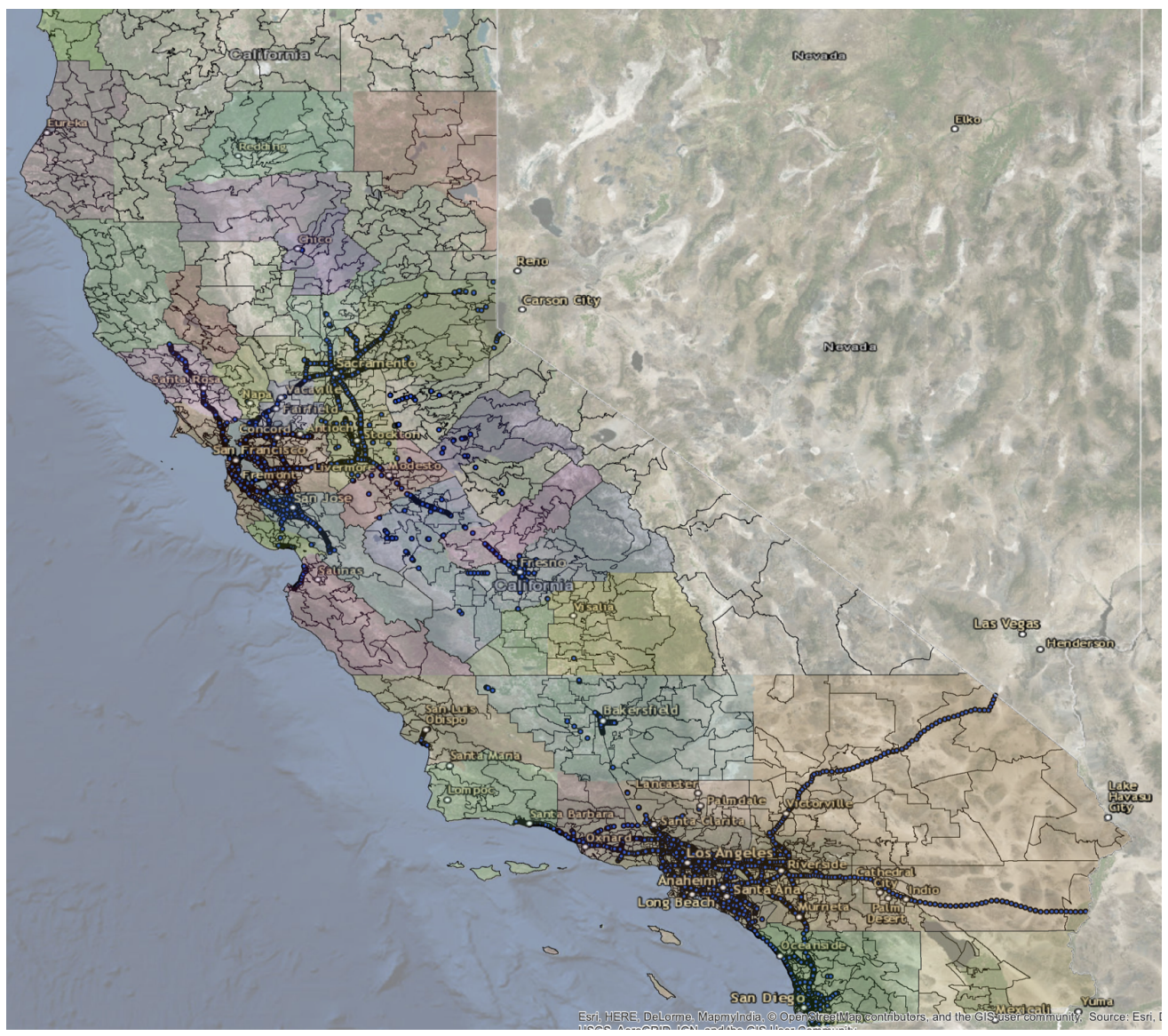

Notes: The figure plots the study location. The points represent traffic monitoring stations, the black outlines are zip codes and the shaded areas are core based statistical areas. 
Since we are concerned with nonlinear effects of traffic congestion we calculate deciles of traffic delay from our traffic panel dataset. Our primary specification uses deciles created from all observations of traffic delay in the dataset (absolute deciles). We also calculate zip code-specific (or relative) deciles based on the time series variation within a zip code. The tenth decile using the aggregate approach represents the $10 \%$ worst traffic over all zip codes and all times. Whereas, the tenth decile in the relative approach represents the $10 \%$ worst traffic that a specific zip code faced. The absolute deciles assume that delay above a certain threshold (roughly $20 \mathrm{mph}$ ) has the same effect in different zip codes. The relative deciles specification assumes that deviations from traditional traffic patterns in a given location is the relevant traffic measure. We believe both are valid metrics of how traffic impacts fire deparments. The two decile specifications are highly correlated, and the results are quite similar using either specification. We provide more detail on the construction of the deciles in Section B of the Appendix.

In order to merge the traffic data to the fire incident data, we assign the most recent five-minute traffic data prior to the alarm being raised. This ensures that the incident did not cause the traffic. We have the exact minute that the alarm was raised, but five-minute intervals for the traffic data. Therefore, the traffic interval will begin 6-10 minutes prior to the alarm being raised. ${ }^{8}$ We also explore other temporal assignments of traffic including up to 60 minutes of traffic and a 10 minute buffer prior to the alarm time. We merge both the traffic delays and the deciles from the panel dataset. Creating the traffic deciles from the full traffic panel prior to merging ensures the traffic deciles are representative of all traffic conditions as opposed to traffic when incidents happen to occur. Since incidents are more likely to occur when traffic is worse (people are awake and moving around) each decile in our merged dataset does not occur with 10\% probability (see Table A.1 in the Appendix). The unit of observation in our dataset is an individual incident and therefore out dataset is not a panel dataset. There are many time periods when no incidents occur in any zip codes and there can be multiple incidents in a zip code during the same time period.

We merge several additional data sets in order to investigate potential policies to mitigate the negative impact of traffic on first responders response times. In order to assess the

\footnotetext{
${ }^{8}$ For example, if the alarm was raised any time between 1:31-1:35 we assign traffic from 1:25-1:30 to that incident.
} 
effect of transportation policies, we use geocoded locations of high-occupancy vehicle lanes (HOV), high-occupancy toll lanes (HOT), and rail stations from the California Department of Transportation. Lastly, we also use the 2010-2014 American Community Survey (ACS) from the Census Bureau to obtain aggregate zip code level characteristics to analyze heterogeneity by demographics. The final dataset contains 1.3 million observations of fire incidents merged with traffic conditions. ${ }^{9}$

Figure 2 shows a histogram of the time it takes for the fire department to arrive on the scene after they receive the alarm (in minutes). The vertical line shows that the average response time the average response time is 6.2 minutes. Table A.2 presents the average and standard deviation in traffic delay by city for all deciles, the 9th decile, and the 10th decile of delay. The 9 th decile represents roughly a $9 \mathrm{mph}$ delay and the average delay in the 10th decile ranges from 20-26 mph depending on the city.

Table A.3 presents the average and standard deviation of delay for each decile for the whole sample. Higher deciles not only have larger average delays but also more variation as shown by the standard deviation within each decile. Figure 3 displays the average traffic delay in mph across all zip codes by time of day. Consistent with most urban areas, Figure 3 shows notable peak traffic in the morning and afternoon.

Traffic in California is a severe issue in several major cites. For example, Los Angeles is a candidate for the worst traffic in the United-States and in the world; six of the country's 10 most congested stretches of highway are in the Los Angeles metropolitan area. Drivers in Los Angeles spent 102 hours a year sitting in traffic during peak hours in 2017. ${ }^{10}$ San Francisco also has severe traffic congestion with the third worst traffic in the United-States behind Los Angeles and New York. The typical driver in the San Francisco area spends an average of 79 hours a year in congestion. The situation is also problematic in other cities in California such as San Diego (48 hours a year in congestion and ranked 13th worst cities in the U.S.) and Sacramento (25 hours a year in congestion). We replicate Figure 3 for each major metropolitan area as well as zip codes not in a major metro area in Figure 4. The

\footnotetext{
${ }^{9}$ We remove response times that are over 5 hours as these are either data errors or not representative of typical operations.

${ }^{10}$ See the INRIX Traffic Scoreboard, available at: http://inrix.com/scorecard/.
} 
Figure 2: Response time

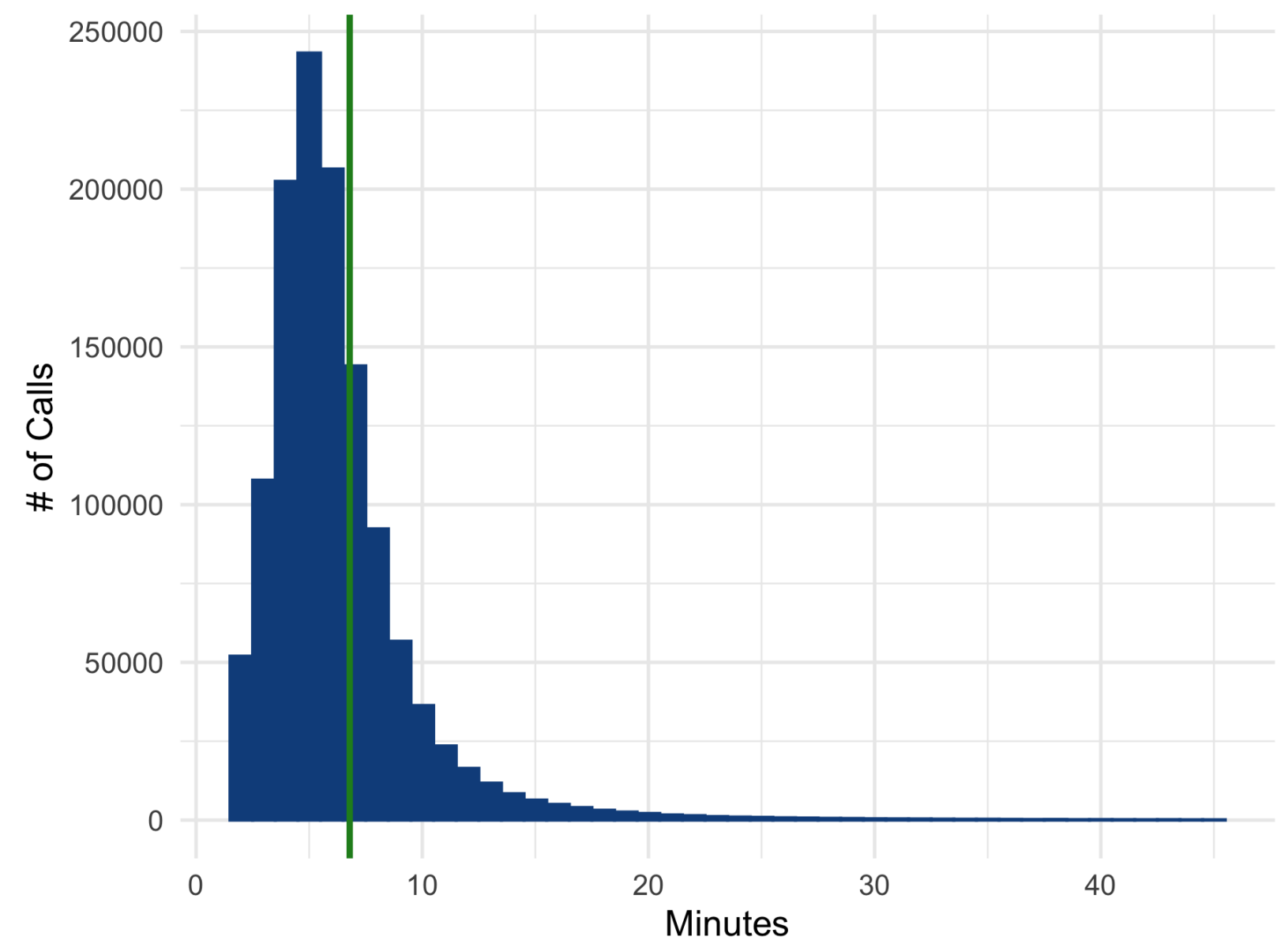

Notes: The figure plots the number of minutes it takes for the fire department to arrive on the scene after they receive the alarm (Response Time) on the horizontal axis. Data are from the NFIRS from 2008-2014. 
Figure 3: Traffic delay by time of day

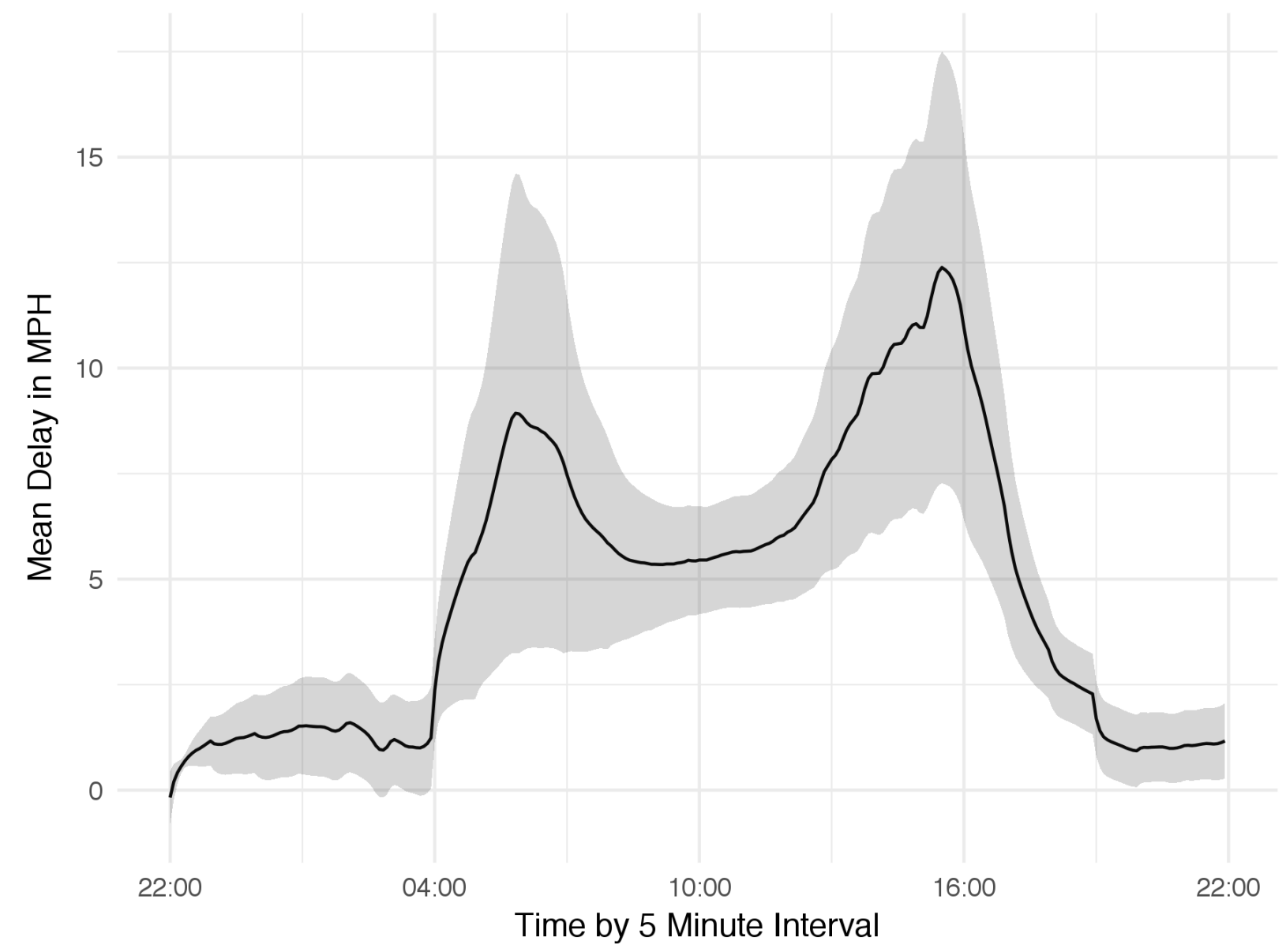

Notes: The solid line plots the average delay in miles per hour (MPH) by time of day and the shaded bands are plus and minus one standard deviation. Data are from the California Department of Transportation Performance Measurement System (PeMS) from 2008-2014.

Bay Area (which includes San Francisco, Oakland, Berkeley, and San Jose) and Los Angeles have the worst traffic followed by San Diego and Sacramento. Zip codes outside of major metro areas (Other) do not typically experience severe delays.

\section{Methodology}

To quantify the impact of traffic on response time and damages, we estimate the following equation:

$$
Y_{i z t}=\beta_{0}+\sum_{k}^{K} \beta_{k} \text { Decile }_{k, z t-1}+\beta_{Z}+\beta_{M Y}+\beta_{D}+\beta_{H}+\epsilon_{i z t}
$$


Figure 4: Traffic delay by time of day across metro areas

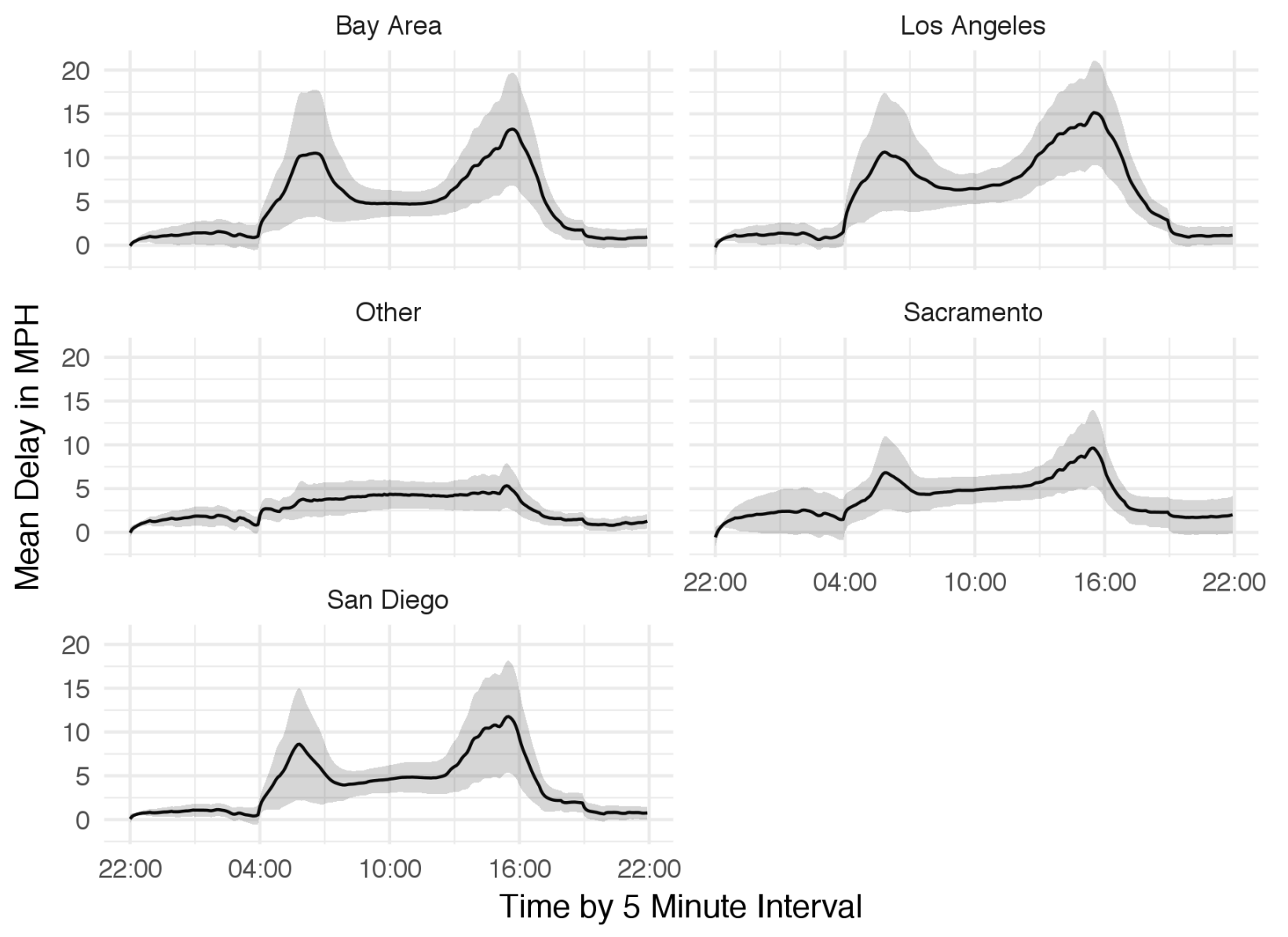

Notes: The solid line plots the average delay in miles per hour (MPH) by time of day for each core based statistical area (CBSA) and the shaded bands are plus and minus one standard deviation. Data are from the California Department of Transportation Performance Measurement System (PeMS). 
where $Y_{i z t}$ is the outcome of interest in for incident $i$ in zip code $z$ at time $t$; our unit of time is a five-minute interval. Our main outcomes of interest are responses time (in minutes) and the natural log of the dollar value of damages from fires. Response time is the time elapsed from when the alarm is sounded until the fire department arrived on the scene in minutes. Our traffic variable is the deviation from free-flow in miles per hours during the five minutes immediately preceding the fire alarm. Decile $e_{k, z t-1}$ is an indicator for the $k^{\text {th }}$ decile of traffic delay in zip code $z$ in the five-minute interval immediately preceding time $t .^{11}$ We use zip code level fixed effects $\left(\beta_{Z}\right)$ to control for static spatial unobserved effects. To control for time-varying unobservables, we include year-by-month $\left(\beta_{M Y}\right)$, day-of-week $\left(\beta_{D}\right)$, and hour of day $\left(\beta_{H}\right)$ fixed effects. Our identifying assumption is that lagged deviations from average traffic in a given zip code, in a given month, on a given day of the week, at a given hour are uncorrelated with response times except through the mechanism of traffic. We posit that traffic congestion is plausibly exogenous because we use traffic before the fire/incident occurs. Our main specification uses cluster-robust standard errors at the zip code level. To better understand the relationship between traffic and response time, we investigate heterogeneous effects along several dimensions: time of day, individual cities and zip code characteristics including average traffic. We also look at several alternative traffic specifications, including different traffic conditions before the alarm is received and alternative definitions of traffic delays. Finally, we analyze policies that can potentially mitigate the results and investigate how these policies affect response times.

\section{Results}

\subsection{Nonlinearities and main results}

First, we document nonlinearities in the effect of traffic congestion on response times. Our dependent variable is the response time in minutes, and we specify the regression using decile indicator variables for lagged traffic delay, where the first decile is omitted to avoid perfect multicollinearity. Since our variable represents deviation from free-flow the first decile represents times where traffic is essentially nonexistent, and all of the coefficients on

\footnotetext{
${ }^{11}$ In our specification, the deciles range from 2 to 10 , where 10 is the worst traffic and 1 is the omitted decile. We omit the first decile so that coefficients on the deciles can be interpreted as relative to the minimum possible traffic.
} 
the included deciles are relative to the omitted first decile. Figure 5 plots the coefficients and 95\% confidence intervals for traffic decile indicators and shows that the impact on response times is concentrated in the two highest deciles (9th and 10th). Traffic in the 10th decile increases response times by about 0.22 minutes, or roughly $3.5 \%$ of the average response time. This is consistent with other research that finds that traffic variability and right tail events, in addition to average congestion, generate significant costs (Beland and Brent, 2018; Gross and Brent, 2018). Given this evidence for highly nonlinear effects, we focus on the 9th and 10th decile of traffic for the remainder of the paper. The green bars in Figure 5 only include the 9 th and 10 th deciles in the regressions; the coefficients are quite similar and we use this parsimonious specification focusing on the right tail of traffic in most of the results. Figure 6 shows the regression results for decile indicators after isolating the sample for each metropolitan area. In all the major metropolitan areas, traffic in the right tail generates most of the increase in response times.

Table 2 presents the primary results of the impact of traffic in the 9th and 10th deciles on response times. The dependent variable is the number of minutes it takes for the fire department to arrive on the scene after they receive the alarm. Column (1) presents results for all observations (fires, all EMS, and all emergency calls) and shows that traffic in the 9th and 10th deciles leads to a significant increase in response times. Columns (2) and (3) present results for fires and EMS calls, respectively and show that traffic increases response times for both fires and EMS calls. The sample for the regression presented in column (4) represents all incidents where rapid response times are critical and is our primary specification for all future regressions except where noted. The sample presented in column (4) includes fires, EMS calls, and incidents where the fire department is dispatched to address incidents involving overpressure rupture, explosion, overheating or hazardous conditions without fires. Column (4) is our preferred specification because it includes all incidents that require a rapid response, and we will refer to this model as our base model. Once again, traffic in the 9th and 10th deciles significantly increase response times. ${ }^{12}$ Our preferred specification in

\footnotetext{
${ }^{12}$ There are more zip codes than fire departments so we prefer using zip code fixed effects in our main specifications. However, some zip codes are served by more than one fire department and there may be unobserved fire department specific effects. Table A.4 in the Appendix presents results using fire departments fixed effects and results are qualitatively the same.
} 
Figure 5: The effect of deciles of traffic on response time

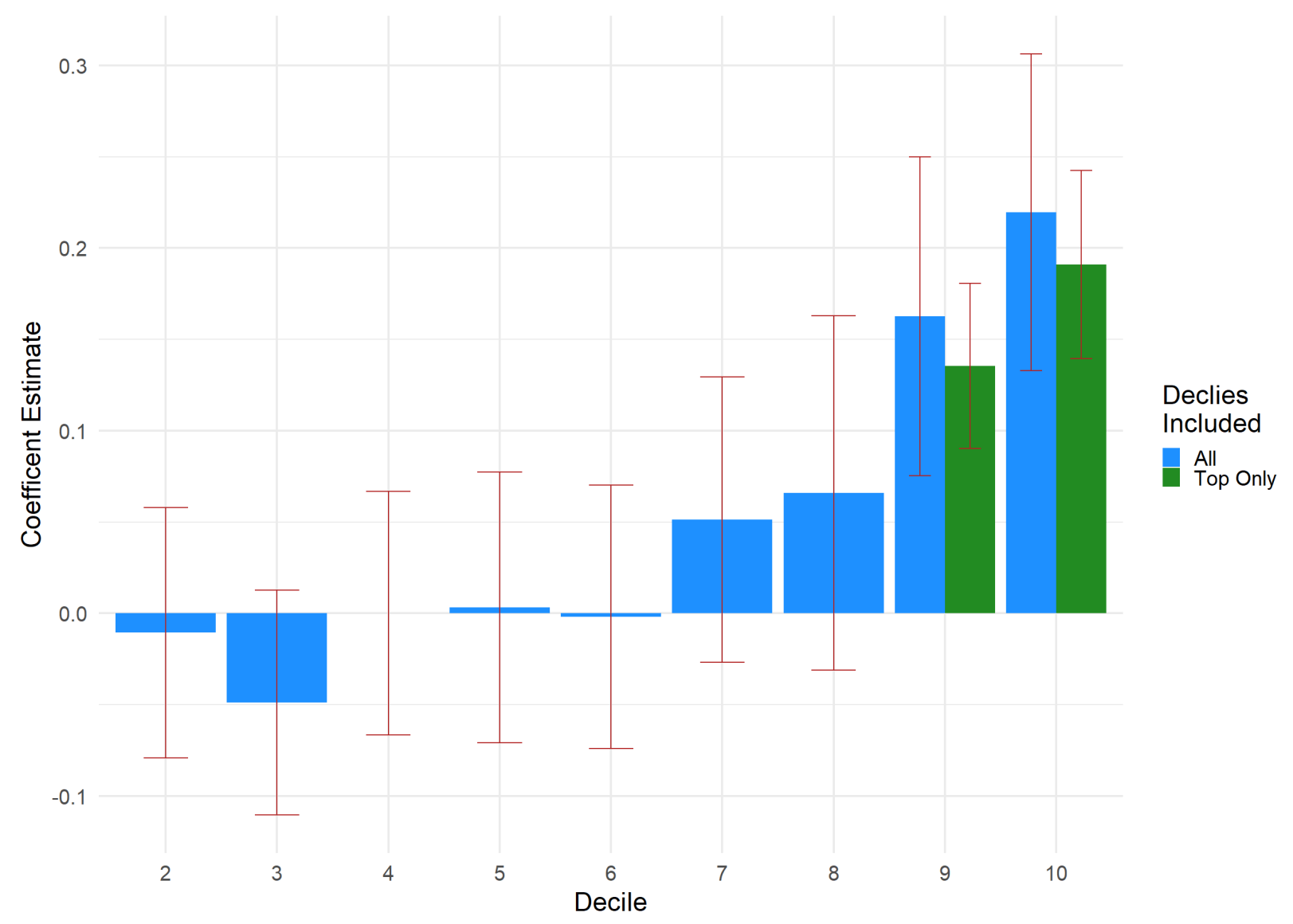

Notes: The figure plots the coefficient for indicators variables for deciles of traffic congestion from a regression where the dependent variable is response time (in minutes). The first decile is omitted to prevent perfect multicollinearity. The regression includes zip code, year-by-month, day-of-week, and hour-of-day fixed effects. The blue bars represent coefficients for estimating equation (1), while the green bars use only the 9 th and 10 th deciles. The $95 \%$ error bars are generated from cluster-robust standard errors at the zip code level. 
Figure 6: The effect of deciles of traffic on response time by metro area

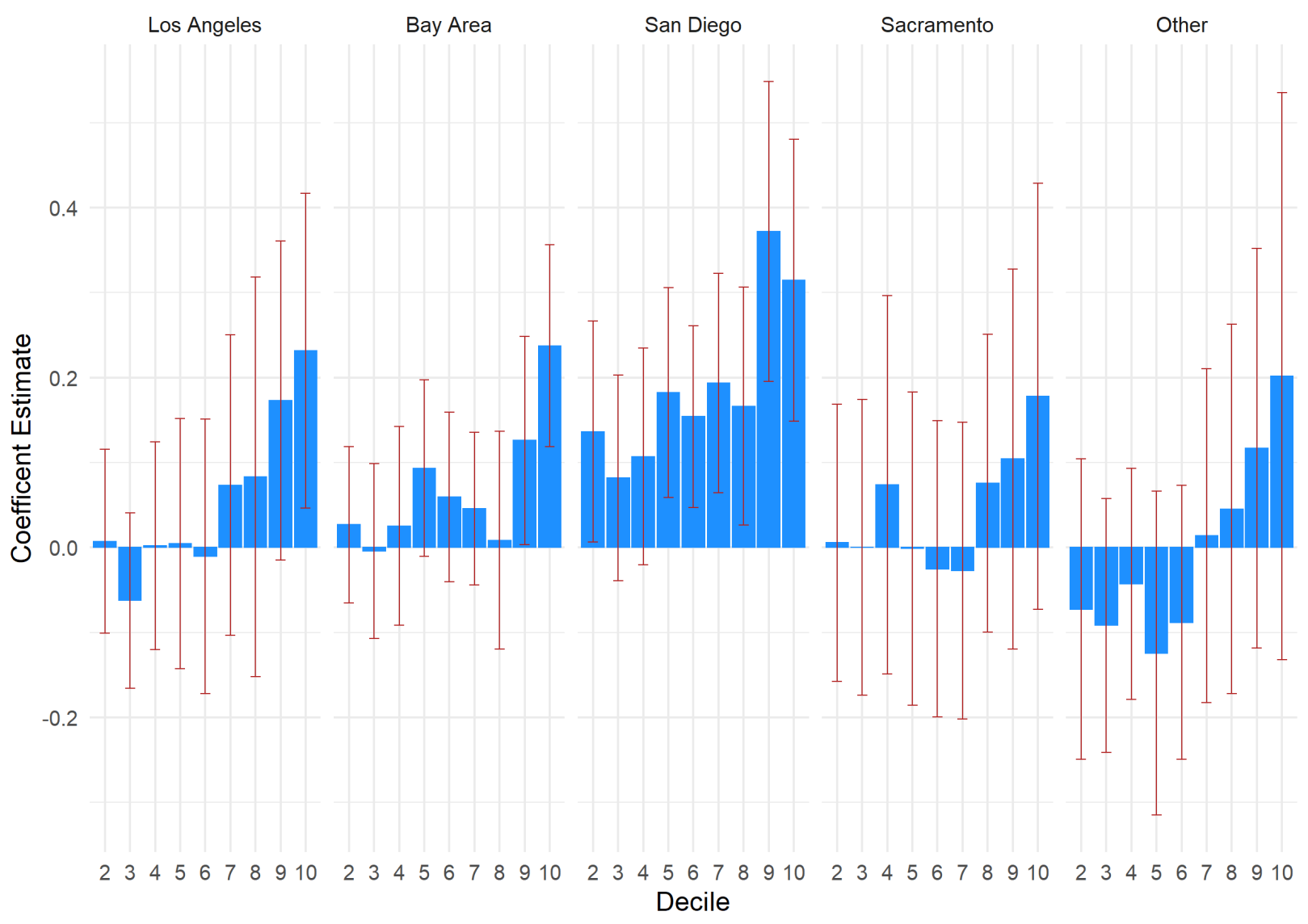

Notes: The figure plots the coefficient for indicators variables for deciles of traffic congestion from regressions where the dependent variable is response time (in minutes). The results are from separate regressions for each core based statistical area (CBSA). Other refers to all zip codes not in one of the major CBSAs listed. The first decile is omitted to prevent perfect multicollinearity. The regressions includes zip code, year-by-month, day-of-week, and hour-of-day fixed effects. The 95\% error bars are generated from cluster-robust standard errors at the zip code level. 
column (4) shows that the increase in response time is 0.135 minutes for the 9 th decile and 0.191 minutes for the 10 th decile, equating respectively to a roughly $2.2 \%$ and $3.1 \%$ increase in response times.

Table 2: The effect of traffic on response time

\begin{tabular}{lcccc}
\hline \hline & $(1)$ & $(2)$ & $(3)$ & $(4)$ \\
& All Observations & Fires & EMS & Emergency Calls \\
\hline Traffic D9 & $0.140^{* * *}$ & $0.146^{* *}$ & $0.0859^{* * *}$ & $0.135^{* * *}$ \\
& $(0.0225)$ & $(0.0661)$ & $(0.0157)$ & $(0.0231)$ \\
Traffic D10 & $0.196^{* * *}$ & $0.173^{* * *}$ & $0.131^{* * *}$ & $0.191^{* * *}$ \\
& $(0.0256)$ & $(0.0626)$ & $(0.0186)$ & $(0.0263)$ \\
\hline Zip Code FEs & Yes & Yes & Yes & Yes \\
Year*Month FEs & Yes & Yes & Yes & Yes \\
Day-of-week FEs & Yes & Yes & Yes & Yes \\
Hour-of-day FEs & Yes & Yes & Yes & Yes \\
Observations & $1,230,652$ & 248,631 & 652,743 & $1,027,770$ \\
Zip Codes & 721 & 709 & 602 & 720 \\
\hline \hline
\end{tabular}

Notes: The dependent variable is the number of minutes it takes for the fire department to arrive on the scene after they receive the alarm (Response Time). Traffic D $i$ refers to the $i^{\text {th }}$ decile of deviations from free-flow. The columns denote subsets of the data for incidents representing fires, all emergency medical services (EMS), and all emergency calls. Emergency calls includes fires, EMS calls as well as incidents where the fire department is dispatched to address incidents involving over-pressure rupture, explosion, overheating or hazardous conditions without fires. Cluster-robust standard errors at the zip code level are in parentheses. ${ }^{*} p<0.10,{ }^{* *} p<0.05,{ }^{* * *} p<0.01$

\subsection{Heterogeneous effects}

We examine heterogeneous impacts for different times of day, locations, and traffic conditions. As shown in Figure 3, traffic congestion varies significantly over the course of the day, so Table 3 displays regressions for the different times of the day. Column (1) presents our base results. Columns (2) and (3) focus on alarms initiated in Peak and Off-Peak hours, respectively. Columns (4) and (5) focus exclusively on morning and evening peak periods. Column (6) interacts the traffic deciles with indicators for morning (AM) and evening (PM) peak periods. Peak refers to alarms initiated in the peak morning (6:00-7:59 AM) and evening (4:00-6:59 PM) commutes, while Off-Peak refers to all other times. Traffic increases response times during all times of the day with the magnitudes highest during the morning peak period. However, the difference across time of day are not significantly different, as shown in column (6).

To examine whether zip codes with different traffic profiles experience different marginal effects, we also run regressions for different subsets of the sample based on zip code level 
Table 3: Heterogeneity in traffic on response time by time of day

\begin{tabular}{lcccccc}
\hline \hline & $(1)$ & $(2)$ & $(3)$ & $(4)$ & $(5)$ & $(6)$ \\
& Base & Peak & Off-Peak & AM Peak & PM Peak & Interaction \\
\hline Traffic D9 & $0.135^{* * *}$ & $0.173^{* * *}$ & $0.112^{* * *}$ & $0.203^{* * *}$ & $0.147^{* * *}$ & $0.104^{* * *}$ \\
& $(0.0231)$ & $(0.0374)$ & $(0.0282)$ & $(0.0765)$ & $(0.0414)$ & $(0.0279)$ \\
Traffic D10 & $0.191^{* * *}$ & $0.199^{* * *}$ & $0.212^{* * *}$ & $0.331^{* * *}$ & $0.146^{* * *}$ & $0.206^{* * *}$ \\
& $(0.0263)$ & $(0.0363)$ & $(0.0428)$ & $(0.0761)$ & $(0.0415)$ & $(0.0402)$ \\
Traffic D9*AM & & & & & & 0.0688 \\
& & & & & $(0.0702)$ \\
Traffic D10*AM & & & & & 0.0487 \\
& & & & & & $(0.0577)$ \\
Traffic D9*PM & & & & & & $(0.0682$ \\
& & & & & & -0.0419 \\
Traffic D10*PM & & & & & $(0.0423)$ \\
& & & & & & Yes \\
Zip Code FEs & Yes & Yes & Yes & Yes & Yes & Yes \\
Year*Month FEs & Yes & Yes & Yes & Yes & Yes & Yes \\
Day-of-week FEs & Yes & Yes & Yes & Yes & Yes & Yes \\
Hour-of-day FEs & Yes & & & & 234,901 & $1,027,770$ \\
Observations & $1,027,770$ & 332,176 & 695,572 & 97,248 & 687 & 720 \\
Zip Codes & 720 & 695 & 714 & 650 & res \\
\hline \hline
\end{tabular}

Notes: The dependent variable is the number of minutes it takes for the fire department to arrive on the scene after they receive the alarm (Response Time) for all emergency calls. Traffic D $i$ refers to the $i^{\text {th }}$ decile of deviations from free-flow. The columns examine different subsets of the sample by time of day. Peak focuses on alarms initiated in the peak congestion (6:00-7:59AM and 4:00-6:59PM), while Off-Peak is all other times The AM and PM Peak columns restrict the sample to morning (6:00-7:59AM) and evening (4:00-6:59PM) respectively. Column (6) interacts the traffic deciles with indicators for morning (AM) and evening (PM) peak periods. Cluster-robust standard errors at the zip code level are in parentheses. ${ }^{*} p<0.10,{ }^{* *} p<0.05,{ }^{* * *} p<0.01$

traffic conditions. Table 4 reports regression results that divide the sample by zip codes' mean and standard deviation of traffic. Column (1) presents the base effects and columns (2) and (3) restrict the sample to zip codes with average delays above and below the sample median, respectively. Columns (4) and (5) present regressions that restrict the sample to zip codes with standard deviation of delays above and below the sample median. Column (6) interacts the traffic deciles with indicator variables for above the median average traffic and above the median standard deviation of traffic. ${ }^{13}$ Table 4 shows that in all four samples, traffic significantly increases response times. The effects are quite consistent across zip codes with different traffic profiles. Column (6) shows that the effect of traffic on response time are smaller (significant at the 10 percent level) for zip codes with higher average traffic. One interpretation is that fire departments adapt to high traffic by investing more resources in locations with high traffic. ${ }^{14}$ We also present graphical evidence of the full distribution of

\footnotetext{
${ }^{13}$ It should be noted that most zip codes with high traffic also have a high standard deviation of traffic.

${ }^{14}$ There is anecdotal evidence of new stations opening to deal with emergencies that occur during rush hour - see https://www.kpbs.org/news/2017/mar/08/study-growing-traffic-increases-fire-department-re/.
} 
effects in high vs. low traffic zip codes in Figure A.1 in the Appendix.

Table 4: Heterogeneity in traffic on response time by traffic conditions

\begin{tabular}{|c|c|c|c|c|c|c|}
\hline & $\begin{array}{l}(1) \\
\text { Base }\end{array}$ & $\begin{array}{c}(2) \\
\text { High Avg. }\end{array}$ & $\begin{array}{c}(3) \\
\text { Low Avg. }\end{array}$ & $\begin{array}{c}(4) \\
\text { High SD }\end{array}$ & $\begin{array}{c}(5) \\
\text { Low SD }\end{array}$ & $\begin{array}{c}6) \\
\text { Interaction }\end{array}$ \\
\hline Traffic D9 & $\begin{array}{l}0.135^{* * *} \\
(0.0231)\end{array}$ & $\begin{array}{c}0.0658^{* * *} \\
(0.0230)\end{array}$ & $\begin{array}{c}0.182^{* * *} \\
(0.0449)\end{array}$ & $\begin{array}{c}0.0983^{* * *} \\
(0.0239)\end{array}$ & $\begin{array}{l}0.157^{* * *} \\
(0.0427)\end{array}$ & $\begin{array}{l}0.177^{* * *} \\
(0.0475)\end{array}$ \\
\hline Traffic D10 & $\begin{array}{l}0.191^{* * *} \\
(0.0263)\end{array}$ & $\begin{array}{l}0.114^{* * *} \\
(0.0274)\end{array}$ & $\begin{array}{l}0.307^{* * *} \\
(0.0678)\end{array}$ & $\begin{array}{l}0.121^{* * *} \\
(0.0249)\end{array}$ & $\begin{array}{l}0.336^{* * *} \\
(0.0737)\end{array}$ & $\begin{array}{l}0.336^{* * *} \\
(0.0762)\end{array}$ \\
\hline Traffic D9*Hi Avg. & & & & & & $\begin{array}{l}-0.120^{*} \\
(0.0688)\end{array}$ \\
\hline Traffic D10*Hi Avg. & & & & & & $\begin{array}{l}-0.0434 \\
(0.0937)\end{array}$ \\
\hline Traffic D9*Hi SD & & & & & & $\begin{array}{c}0.0514 \\
(0.0646)\end{array}$ \\
\hline Traffic D10*Hi SD & & & & & & $\begin{array}{c}-0.145 \\
(0.0993)\end{array}$ \\
\hline Zip Code FEs & Yes & Yes & Yes & Yes & Yes & Yes \\
\hline Year*Month FEs & Yes & Yes & Yes & Yes & Yes & Yes \\
\hline Day-of-week FEs & Yes & Yes & Yes & Yes & Yes & Yes \\
\hline Hour-of-day FEs & Yes & Yes & Yes & Yes & Yes & Yes \\
\hline Observations & $1,027,770$ & 519,549 & 508,221 & 529,079 & 498,691 & $1,027,770$ \\
\hline Zip Codes & 720 & 381 & 339 & 386 & 334 & 720 \\
\hline
\end{tabular}

Notes: The dependent variable is the number of minutes it takes for the fire department to arrive on the scene after they receive the alarm (Response Time) for all emergency calls. Traffic D $i$ refers to the $i^{\text {th }}$ decile of deviations from free-flow. The columns examine different subsets based on zip code level traffic conditions. The High and Low Traffic columns restrict the sample to zip codes with average delays above and below the sample median. The High and Low Std. Dev. columns restrict the sample to zip codes with standard deviation of delays above and below the sample median. Column (6) interacts the traffic deciles with indicators for high average and standard deviation traffic zip codes. Cluster-robust standard errors at the zip code level are in parentheses. ${ }^{*} p<0.10,{ }^{* *} p<0.05,{ }^{* * *} p<0.01$

Next, we explore the role of expected vs unexpected traffic. We estimate moving average models to predict traffic and then calculate deciles from both the predicted values and the residuals that we use as regressors, which we refer to as Expected and Unexpected, respectively. The moving average regressions include all fixed effects as our base specification along with recent traffic. The columns show different specifications for predicting our primary independent variable: zip code level traffic prior to a fire alarm. The rationale behind using different moving average predictions is to proxy for the (unknown) prediction model that fire departments use when dispatching vehicles to an emergency given the observable characteristics of the emergency. ${ }^{15}$ Columns (1) and (2) present moving average models using the traffic observations for the most recent week and month, respectively, using the traffic during the exact same hour of the day. Columns (3) and (4) present a similar specification

\footnotetext{
${ }^{15}$ First Stage shows the coefficient on the moving average variable in the first stage regression - a perfect prediction will have a value of one. Both the residuals and predicted values are standardized. We present in the Appendix the details of how the different moving average are calculated.
} 
for traffic in the last week or month but expand the temporal period used to predict traffic to all hours during the same peak period (AM, PM, or Off-Peak). The results in Table 5 are substantially larger for unexpected extreme traffic, which suggests habituation and adaptation by first responders to traffic conditions. When fire departments expect high traffic they can still respond quickly but are delayed by unexpected traffic. Section $\mathrm{C}$ of the Appendix describes the moving average model in more detail.

Table 5: Heterogeneity in traffic on response time by traffic expectations

\begin{tabular}{|c|c|c|c|c|}
\hline & \multicolumn{2}{|c|}{ Hour } & \multicolumn{2}{|c|}{ Peak } \\
\hline & $(1)$ & $(2)$ & $(3)$ & $(4)$ \\
\hline & Week & Month & Week & Month \\
\hline \multirow[t]{2}{*}{ Expected D9 } & 0.0366 & 0.0300 & -0.0170 & 0.0128 \\
\hline & $(0.0260)$ & $(0.0262)$ & $(0.0264)$ & $(0.0255)$ \\
\hline \multirow[t]{2}{*}{ Expected D10 } & 0.00254 & -0.0139 & -0.0326 & -0.0208 \\
\hline & $(0.0313)$ & $(0.0343)$ & $(0.0323)$ & $(0.0322)$ \\
\hline \multirow[t]{2}{*}{ Unexpected D9 } & $0.0788^{* * *}$ & $0.0710^{* * *}$ & $0.0771^{* * *}$ & $0.0675^{* * *}$ \\
\hline & $(0.0213)$ & $(0.0219)$ & $(0.0222)$ & $(0.0216)$ \\
\hline \multirow[t]{2}{*}{ Unexpected D10 } & $0.158^{* * *}$ & $0.143^{* * *}$ & $0.185^{* * *}$ & $0.171^{* * *}$ \\
\hline & $(0.0221)$ & $(0.0231)$ & $(0.0301)$ & $(0.0283)$ \\
\hline First Stage & .89 & .96 & .75 & .58 \\
\hline Zip Code FEs & Yes & Yes & Yes & Yes \\
\hline Year*Month FEs & Yes & Yes & Yes & Yes \\
\hline Day-of-week FEs & Yes & Yes & Yes & Yes \\
\hline Hour-of-day FEs & Yes & Yes & Yes & Yes \\
\hline Observations & $1,027,770$ & $1,027,770$ & $1,027,770$ & $1,027,770$ \\
\hline Zip Codes & 720 & 720 & 720 & 720 \\
\hline
\end{tabular}

Notes: The dependent variable is the number of minutes it takes for the fire department to arrive on the scene after they receive the alarm (Response Time) for all emergency calls. Residual and Prediction refer to the residuals and predicted values from a moving average regression with all fixed effects and recent delays. The columns show different specifications for the month average; either the previous week or month and using the same our or same peak period (AM, PM or Off-Peak). First Stage shows the coefficient on the moving average variable in the first stage regression a perfect prediction will have a value of one. Both the residuals and predicted values are standardized. Cluster-robust standard errors at the zip code level are in parentheses. ${ }^{*} p<0.10,{ }^{* *} p<0.05,{ }^{* * *} p<0.01$

Table A.5 investigates the effect of traffic on response time by zip code characteristics. Column (1) presents our base specification. Columns (2) and (3) present the results for high and low income areas, respectively, and columns (4) and (5) present results for high and low non-white areas, respectively. Column (6) interacts indicators for high income and high non-white zip codes with traffic deciles. High income refers to zip codes above the sample median for median household income and high non-white refer to zip codes that are 
above the sample median for the percentage of people that are not white. Table A.5 shows that traffic significantly increases response times in all areas, and there are no statistically significant differences across zip codes with different demographic characteristics.

\subsection{Robustness}

In order to test whether alternative confounding effects are driving the results, we investigate the robustness of the results to different levels of fixed effects, clustering, and specifications of the traffic variable. Our first set of robustness results, presented in Table 6 shows a variety of different sets of fixed effects and clusters for the standard errors. Column (1) replicates the base effect, column (2) replaces year-by-month fixed effects with date fixed effects, column (3) replaces year-by-month fixed effects with metro-by-date fixed effects, ${ }^{16}$ and column (4) interacts all temporal fixed effects (year-by-month, hour-of-day, and day-of-week) with zip code fixed effects. Columns (5) and (6) replicate the most conservative specification presented in column (4) but employ two way clustering for zip code and year-by-month and zip code and hour-of-day, respectively. Table 6 shows that the results are robust to all the alternative specifications and the coefficients are very similar across all columns.

There are more zip codes than fire departments so we prefer using zip code fixed effects in our main specifications. However, some zip codes are served by more than one fire department and there may be unobserved fire department specific effects. Therefore, we also replicate these specifications using both zip code and fire department fixed effects as well as including fire departments as an additional cluster in the standard errors. The results are essentially unchanged and are reported in Table A.6 in the Appendix.

Our main specification uses deciles generated from all observations in the traffic panel. In Table 7, we calculate deciles based on the time series variation within a zip code. The relative definition may better reflect the differences in infrastructure and typical traffic patterns in a given location. The results are qualitatively the same. Tables A.7 and A.8 in the Appendix replicate Table 2 and 5 using the relative measure of traffic and the results are essentially unchanged. We also show the effect for all deciles using the absolute and relative measures

\footnotetext{
${ }^{16}$ Metro-by-date fixed effects generate a different fixed effect for every date in every metropolitan area, including the "Other" designation.
} 
Table 6: Robustness to different specifications

\begin{tabular}{lcccccc}
\hline \hline & $(1)$ & $(2)$ & $(3)$ & $(4)$ & $(5)$ & $(6)$ \\
& Base & Date & Metro*Date & Zip*All & Zip*All & Zip*All \\
\hline Traffic D9 & $0.135^{* * *}$ & $0.110^{* * *}$ & $0.0958^{* * *}$ & $0.113^{* * *}$ & $0.113^{* * *}$ & $0.113^{* * *}$ \\
& $(0.0231)$ & $(0.0230)$ & $(0.0218)$ & $(0.0211)$ & $(0.0264)$ & $(0.0195)$ \\
Traffic D10 & $0.191^{* * *}$ & $0.162^{* * *}$ & $0.149^{* * *}$ & $0.164^{* * *}$ & $0.164^{* * *}$ & $0.164^{* * *}$ \\
& $(0.0263)$ & $(0.0251)$ & $(0.0237)$ & $(0.0236)$ & $(0.0334)$ & $(0.0291)$ \\
\hline Zip Code FEs & Yes & Yes & Yes & No & No & No \\
Year*Month FEs & Yes & No & No & No & No & No \\
Day-of-week FEs & Yes & Yes & Yes & No & No & No \\
Hour-of-day FEs & Yes & Yes & Yes & No & No & No \\
Date FEs & No & Yes & No & No & No & No \\
Metro*Date FEs & No & No & Yes & No & No & No \\
Zip*Year*Month FEs & No & No & No & Yes & Yes & Yes \\
Zip*Day-of-week FEs & No & No & No & Yes & Yes & Yes \\
Zip*Hour-of-day & No & No & No & Yes & Yes & Yes \\
SE Cluster & Zip & Zip & Zip & Zip & Zip \& Month & Zip \& Hour \\
Observations & $1,027,770$ & $1,027,764$ & $1,027,659$ & $1,021,476$ & $1,021,476$ & $1,021,476$ \\
Zip Codes & 720 & 720 & 720 & 635 & 635 & 635 \\
\hline \hline
\end{tabular}

Notes: The dependent variable is the number of minutes it takes for the fire department to arrive on the scene after they receive the alarm (Response Time) for all emergency calls. Traffic D $i$ refers to the $i^{t h}$ decile of deviations from free-flow. The columns examine different levels of fixed effects and two way clustering of the standard errors. Cluster-robust standard errors at the level described in the bottom panel are in parentheses. ${ }^{*} p<0.10,{ }^{* *} p<0.05$, *** $p<0.01$

in Figure A.2 in the Appendix. Table A.9 present results without weighting by station occupency and the results are qualitatively the same.

In Table A.10, we also regress the average delay (instead of using deciles) on response times for all the specifications presented in Table 6. Our traffic variables is the standardized average delay, so the interpretation of the coefficients is the change in response times for a one standard deviation increase in traffic delay. The effect of average traffic on response times is positive and significant in all specifications, which shows there are average effects even though they are highly nonlinear.

Next, we investigate different temporal specifications of the traffic variable. Our primary specification uses traffic in the previous five minutes using a five minutes lag from when the alarm was raised. Table 8 presents different traffic specifications to estimate the impact of traffic on response times. The first five columns use a five-minute lag before the alarm but expand the historical window of traffic used to generate the congestion variable. The last three columns use a ten minute lag before the alarm was raised and various times to 
Table 7: Robustness to different specifications - zip code-specific deciles

\begin{tabular}{lcccccc}
\hline \hline & $(1)$ & $(2)$ & $(3)$ & $(4)$ & $(5)$ & $(6)$ \\
& Base & Date & Metro*Date & Zip*All & Zip*All & Zip*All \\
\hline Traffic D9 & $0.0863^{* * *}$ & $0.0674^{* * *}$ & $0.0559^{* * *}$ & $0.0727^{* * *}$ & $0.0727^{* * *}$ & $0.0727^{* * *}$ \\
& $(0.0227)$ & $(0.0222)$ & $(0.0208)$ & $(0.0186)$ & $(0.0204)$ & $(0.0215)$ \\
Traffic D10 & $0.176^{* * *}$ & $0.144^{* * *}$ & $0.125^{* * *}$ & $0.160^{* * *}$ & $0.160^{* * *}$ & $0.160^{* * *}$ \\
& $(0.0267)$ & $(0.0255)$ & $(0.0249)$ & $(0.0222)$ & $(0.0293)$ & $(0.0289)$ \\
\hline Zip Code FEs & Yes & Yes & Yes & No & No & No \\
Year*Month FEs & Yes & No & No & No & No & No \\
Day-of-week FEs & Yes & Yes & Yes & No & No & No \\
Hour-of-day FEs & Yes & Yes & Yes & No & No & No \\
Date FEs & No & Yes & No & No & No & No \\
Metro*Date FEs & No & No & Yes & No & No & No \\
Zip*Year*Month FEs & No & No & No & Yes & Yes & Yes \\
Zip*Day-of-week FEs & No & No & No & Yes & Yes & Yes \\
Zip*Hour-of-day & No & No & No & Yes & Yes & Yes \\
SE Cluster & Zip & Zip & Zip & Zip & Zip \& Month & Zip \& Hour \\
Observations & $1,027,770$ & $1,027,764$ & $1,027,659$ & $1,021,476$ & $1,021,476$ & $1,021,476$ \\
Zip Codes & 720 & 720 & 720 & 635 & 635 & 635 \\
\hline \hline
\end{tabular}

Notes: The dependent variable is the number of minutes it takes for the fire department to arrive on the scene after they receive the alarm (Response Time) for all emergency calls. Traffic D $i$ refers to the $i^{\text {th }}$ zip code-specific decile of deviations from free-flow. The columns examine different levels of fixed effects and two way clustering of the standard errors. Cluster-robust standard errors at the level described in the bottom panel are in parentheses. ${ }^{*} p<0.10,{ }^{* *}$ $p<0.05,{ }^{* * *} p<0.01$

generate the traffic conditions. ${ }^{17}$ In all specifications, the results are robust to different ways of calculating traffic congestion.

\subsection{Policy investigation}

In order to understand how municipalities are coping with the effect of traffic on first responders, we investigate how road congestion policies (HOV lanes, toll roads, and public transportation) and fire department resources mitigate the negative impact of traffic on response times. Local and state policies are implemented for many reasons, some of which may be correlated with emergency response times. In this section, we investigate whether these policies mitigate the marginal effect of traffic on response times. The transportation policies we consider are not time varying and are nested within the zip codes. Therefore, our zip code fixed effects absorb the base effect of the policy on response times, and our identifying variation is based on the interaction of static policies with quasi-randomly assigned traf-

\footnotetext{
${ }^{17}$ If an alarm was raised at 11:50 the base specification ( 5 min with 5 min lag) uses traffic from 11:40-11:45. The 30 min with 5 min lag will use traffic from 11:15-11:45, and the 30 min with 10 min lag uses traffic from 11:10-11:40.
} 
Table 8: Robustness to different traffic variables

\begin{tabular}{|c|c|c|c|c|c|c|c|c|}
\hline & \multicolumn{5}{|c|}{ 5min Lag } & \multicolumn{3}{|c|}{ 10min Lag } \\
\hline & (1) & $(2)$ & (3) & (4) & (5) & (6) & (7) & (8) \\
\hline & $5 \mathrm{~min}$ & $10 \mathrm{~min}$ & $20 \mathrm{~min}$ & $30 \mathrm{~min}$ & $60 \mathrm{~min}$ & $5 \mathrm{~min}$ & $30 \mathrm{~min}$ & $60 \mathrm{~min}$ \\
\hline \multirow[t]{2}{*}{ Traffic D9 } & $0.135^{* * *}$ & $0.132^{* * *}$ & $0.133^{* * *}$ & $0.122^{* * *}$ & $0.116^{* * *}$ & $0.140^{* * *}$ & $0.124^{* * *}$ & $0.126^{* * *}$ \\
\hline & $(0.0231)$ & $(0.0244)$ & $(0.0249)$ & $(0.0232)$ & $(0.0241)$ & $(0.0249)$ & $(0.0234)$ & $(0.0242)$ \\
\hline \multirow{2}{*}{ Traffic D10 } & $0.191^{* * *}$ & $0.162^{* * *}$ & $0.161^{* * *}$ & $0.161^{* * *}$ & $0.150^{* * *}$ & $0.156^{* * *}$ & $0.157^{* * *}$ & $0.146^{* * *}$ \\
\hline & $(0.0263)$ & $(0.0269)$ & $(0.0270)$ & $(0.0277)$ & $(0.0298)$ & $(0.0275)$ & $(0.0279)$ & $(0.0293)$ \\
\hline Zip Code FEs & Yes & Yes & Yes & Yes & Yes & Yes & Yes & Yes \\
\hline Year*Month FEs & Yes & Yes & Yes & Yes & Yes & Yes & Yes & Yes \\
\hline Day-of-week FEs & Yes & Yes & Yes & Yes & Yes & Yes & Yes & Yes \\
\hline Hour-of-day FEs & Yes & Yes & Yes & Yes & Yes & Yes & Yes & Yes \\
\hline Observations & $1,027,770$ & $1,027,769$ & $1,027,769$ & $1,027,769$ & $1,027,769$ & $1,025,217$ & $1,025,217$ & $1,025,217$ \\
\hline Zip Codes & 720 & 720 & 720 & 720 & 720 & 720 & 720 & 720 \\
\hline
\end{tabular}

Notes: The dependent variable is the number of minutes it takes for the fire department to arrive on the scene after they receive the alarm (Response Time) for all emergency calls. Traffic D $i$ refers to the $i^{\text {th }}$ decile of deviations from free-flow. The columns examine different ways to create the traffic conditions prior to the alarm. Cluster-robust standard errors at the zip code level are in parentheses. ${ }^{*} p<0.10,{ }^{* *} p<0.05,{ }^{* * *} p<0.01$

fic. This alleviates concern over any static unobservable correlation between transportation policies and response times.

First, we analyze policies that attempt to reduce traffic congestion. We create indicator variables for zip codes that have HOV lanes, toll roads, rail stations and metro stations. Table 9 presents the results of these regressions that subset the sample by these variables and then generates an interaction with being above the 9th decile (grouping the 9th and 10th decile together). Column (1) presents the base effect for reference, and column (2) shows the results for zip codes that do not have any of the aforementioned policies. Columns (3) - (6) show the results for the subset of zip codes that have at least one HOV lane, toll lane, rail station, and metro station. ${ }^{18}$ Lastly, column (7) shows the interactions. The marginal effect of traffic is largest in the zip codes without any of these policies, and smallest in zip codes with HOV lanes. In the interaction model the difference in marginal effect is statistically significant for HOV lanes but none of the other policies. In addition to decreasing congestion as found in the literature, HOV lanes appear to mitigate the marginal effect of congestion on response times. ${ }^{19}$ One explanation is that emergency response vehicles can access the

\footnotetext{
${ }^{18}$ Metro stations are a subset of rail stations that focus on local transportation. By contrast, rail stations also include longer distance (inter-city) rail lines.

${ }^{19}$ Rail, Metro stations, Toll and HOV lanes are implemented by cities for a multitude of reasons. It is possible that these policies were put in place, partly, in response to the negative effect of traffic on response time. This could affect the interpretation of the results of this section.
} 
less-congested HOV lanes during an emergency.

Table 9: Interactions with Tolling and Public Transport

\begin{tabular}{|c|c|c|c|c|c|c|c|}
\hline & $\begin{array}{c}(1) \\
\text { Base }\end{array}$ & $\begin{array}{c}(2) \\
\text { None }\end{array}$ & $\begin{array}{c}(3) \\
\text { HOV }\end{array}$ & $\begin{array}{l}(4) \\
\text { Toll }\end{array}$ & $\begin{array}{c}\text { (5) } \\
\text { Rail }\end{array}$ & $\begin{array}{l}\text { (6) } \\
\text { Metro }\end{array}$ & $\begin{array}{c}(7) \\
\text { Interactions }\end{array}$ \\
\hline \multirow[t]{2}{*}{ Traffic D9 } & $0.135^{* * *}$ & $0.169^{* * *}$ & $0.101^{* * *}$ & $0.207^{* * *}$ & $0.0881^{* * *}$ & $0.0666^{*}$ & $0.176^{* * *}$ \\
\hline & $(0.0231)$ & $(0.0476)$ & $(0.0284)$ & $(0.0445)$ & $(0.0327)$ & $(0.0397)$ & $(0.0358)$ \\
\hline \multirow[t]{2}{*}{ Traffic D10 } & $0.191^{* * *}$ & $0.270^{* * *}$ & $0.0905^{* * *}$ & $0.138^{* * *}$ & $0.191^{* * *}$ & $0.161^{* * *}$ & $0.232^{* * *}$ \\
\hline & $(0.0263)$ & $(0.0511)$ & $(0.0308)$ & $(0.0395)$ & $(0.0485)$ & $(0.0527)$ & $(0.0373)$ \\
\hline \multirow[t]{2}{*}{ Traffic D9 or D10*HOV } & & & & & & & $-0.0811^{* *}$ \\
\hline & & & & & & & $(0.0384)$ \\
\hline \multirow[t]{2}{*}{ Traffic D9 or D10*Toll } & & & & & & & 0.0406 \\
\hline & & & & & & & $(0.0454)$ \\
\hline \multirow[t]{2}{*}{ Traffic D9 or D10*Rail } & & & & & & & -0.0612 \\
\hline & & & & & & & $(0.0565)$ \\
\hline \multirow[t]{2}{*}{ Traffic D9 or D10*Metro } & & & & & & & 0.0303 \\
\hline & & & & & & & $(0.0642)$ \\
\hline Zip Code FEs & Yes & Yes & Yes & Yes & Yes & Yes & Yes \\
\hline Year*Month FEs & Yes & Yes & Yes & Yes & Yes & Yes & Yes \\
\hline Day-of-week FEs & Yes & Yes & Yes & Yes & Yes & Yes & Yes \\
\hline Hour-of-day FEs & Yes & Yes & Yes & Yes & Yes & Yes & Yes \\
\hline Observations & $1,027,770$ & 406,808 & 431,888 & 204,086 & 224,092 & 116,391 & $1,027,770$ \\
\hline Zip Codes & 720 & 278 & 319 & 182 & 154 & 80 & 720 \\
\hline
\end{tabular}

Notes: The dependent variable is the number of minutes it takes for the fire department to arrive on the scene after they receive the alarm (Response Time) for all emergency calls. Traffic D $i$ refers to the $i^{t h}$ decile of deviations from free-flow. Table 9 presents the results of these regressions that subset the sample by these variables and then generates an interaction with being above the 9th decile (grouping the 9th and 10th decile together). Column (1) presents the base effect for reference, and column (2) shows the results for zip codes that do not have any of the aforementioned policies. Columns (3) - (6) show the results for the subset of zip codes that have at least one HOV lane, toll lane, rail station, and metro station. Lastly, column (7) shows the interactions. Toll is equal to one if the zip code has toll roads, Rail is equal to one if there are rail stations in the zip code, and Metro is equal to one if there is a municipal metro station in the zip code. Cluster-robust standard errors at the zip code level are in parentheses. ${ }^{*} p<0.10,{ }^{* *} p<0.05,{ }^{* * *} p<0.01$

Municipalities may also provide additional resources to fire departments to reduce response times. One potential policy to reduce response times is to build more fire stations. The number of fires stations will reduce the expected distance between an incident and the nearest fires station. Table 10 investigates the impact of traffic on response time based on the number of fire stations per zip code. Our sample is limited to Los Angeles County due to the availability of spatially explicit data on all fire stations. While we do not have the geographic location of the specific station that was dispatched to a given incident, we attempt to proxy for distance by using the number of stations within a zip code. The assumption is that an incident in a zip code with more stations is more likely to have a nearby station relative to incidents that occur in zip codes with fewer stations. The first column investigates the base impact in Los Angeles County. ${ }^{20}$ Column (2) limits the sample to zip codes with fewer than

\footnotetext{
${ }^{20}$ Our definition of the Los Angeles CBSA includes locations outside of Los Angeles County (e.g. Anaheim) that
} 
2 fire stations (low stations), which is the median number of stations per zip code. Column (3) limits the sample to zip codes with 2 or more fire stations (high stations). Column (4) interacts the number of stations with our traffic deciles. Table 10 suggests that there are limited impact of having more fire stations in the zip code. This suggest that the number of fire stations in a given zip code is not a determining factor to mitigate the negative impact of traffic on response times. One explanation is that fire stations in urban areas are well distributed geographically, and the distance from a station to an incident is not the primary predictor of response times. ${ }^{21}$

Table 10: Effect of traffic on response time based on the number of fire stations per zip code in Los Angeles

\begin{tabular}{lcccc}
\hline \hline & $(1)$ & $(2)$ & $(3)$ & $(4)$ \\
& Base LA & Low Stations & High Stations & Interactions \\
\hline Traffic D9 & $0.0897^{* *}$ & $0.122^{* *}$ & 0.0697 & $0.0887^{* *}$ \\
& $(0.0411)$ & $(0.0568)$ & $(0.0589)$ & $(0.0405)$ \\
Traffic D10 & $0.145^{* * *}$ & $0.190^{* * *}$ & $0.106^{*}$ & $0.144^{* * *}$ \\
& $(0.0454)$ & $(0.0703)$ & $(0.0591)$ & $(0.0445)$ \\
Traffic D9*Stations & & & & 0.00504 \\
& & & & $(0.0408)$ \\
Traffic D10*Stations & & & & -0.0429 \\
& & Yes & Yes & Yes \\
Zip Code FEs & Yes & Yes & Yes & Yes \\
Year*Month FEs & Yes & Yes & Yes & Yes \\
Day-of-week FEs & Yes & Yes & Yes & Yes \\
Hour-of-day FEs & Yes & 63,706 & 87,830 & 151,536 \\
Observations & 151,536 & 83 & 82 & 165 \\
Zip Codes & 165 & & & \\
\hline \hline
\end{tabular}

Notes: The dependent variable is the number of minutes it takes for the fire department to arrive on the scene after they receive the alarm (Response Time) for all emergency calls. Traffic D $i$ refers to the $i^{\text {th }}$ decile of deviations from free-flow. The first column investigate the base impact in Los Angeles. Column (2) limits the sample to zip codes with smaller than 2 fire stations. Column (3) limits the sample to zip codes with 2 or more fire stations. Column (4) uses interaction terms. Cluster-robust standard errors at the zip code level are in parentheses. ${ }^{*} p<0.10,{ }^{* *}$ $p<0.05,{ }^{* * *} p<0.01$

Another way of evaluating the interaction of traffic and fire department resources is accounting for the intensity of emergency response calls at a given time. We assess the effect of strained fire department resources by constructing two variables for the number of incidents at a given time. The first counts the number of incidents in a zip code during a

are not served by the Los Angeles City or County fire departments. The goal of defining CBSAs is to examine regions with different traffic patterns as opposed to fire departments.

${ }^{21}$ The spatial distribution of fire stations in Los Angeles County is presented visually in Figure A.3 in the Appendix. Figure A.3 shows that fire stations are well-distributed geographically in the inhabited parts of the city. 
given hour and the second counts all incidents for a fire department in a given hour. The first column in Table 11 reproduces our base results. Column (2) controls for the number of incidents within a zip code and column (4) controls for the number of incidents at the fire department level. Columns (2) and (4) show that controlling for the total number of incidents does not significantly change the base effect of traffic on response time. Columns (3) and (5) interact the incident counts with traffic deciles. Once again, the base effects of traffic on response time remains qualitatively the same. In column (5), the interaction between the 10th traffic decile and the number of emergency calls at the fire department is positive and significant, indicating that the number of calls increases the marginal effect of traffic. The incident count is positive and significant in all specifications, meaning that more incidents lead to a longer response times as resources are strained. 
Table 11: The effect of traffic on response times while accounting for multiple incidents

\begin{tabular}{|c|c|c|c|c|c|}
\hline & & \multicolumn{2}{|r|}{ Zip } & \multicolumn{2}{|c|}{ Fire Department } \\
\hline & $(1)$ & $(2)$ & $(3)$ & $(4)$ & $(5)$ \\
\hline & Base & Count & Traffic*Count & Count & Traffic* Count \\
\hline \multirow[t]{2}{*}{ Traffic D9 } & $0.135^{* * *}$ & $0.129^{* * *}$ & $0.129^{* * *}$ & $0.130^{* * *}$ & $0.129^{* * *}$ \\
\hline & $(0.0231)$ & $(0.0228)$ & $(0.0228)$ & $(0.0229)$ & $(0.0228)$ \\
\hline \multirow[t]{2}{*}{ Traffic D10 } & $0.191^{* * *}$ & $0.181^{* * *}$ & $0.180^{* * *}$ & $0.182^{* * *}$ & $0.175^{* * *}$ \\
\hline & $(0.0263)$ & $(0.0260)$ & $(0.0262)$ & $(0.0259)$ & $(0.0266)$ \\
\hline \multirow[t]{2}{*}{ Zip Count } & & $0.188^{* * *}$ & $0.180^{* * *}$ & & \\
\hline & & $(0.0235)$ & $(0.0262)$ & & \\
\hline \multirow[t]{2}{*}{ FD Count } & & & & $0.139^{* * *}$ & $0.131^{* * *}$ \\
\hline & & & & $(0.0337)$ & $(0.0349)$ \\
\hline \multirow[t]{2}{*}{ Traffic D9*Zip Count } & & & 0.0262 & & \\
\hline & & & $(0.0321)$ & & \\
\hline \multirow[t]{2}{*}{ Traffic D10*Zip Count } & & & 0.0430 & & \\
\hline & & & $(0.0335)$ & & \\
\hline \multirow[t]{2}{*}{ Traffic D9*FD Count } & & & & & -0.0135 \\
\hline & & & & & $(0.0218)$ \\
\hline \multirow[t]{2}{*}{ Traffic D10*FD Count } & & & & & $0.0561^{* *}$ \\
\hline & & & & & $(0.0256)$ \\
\hline Zip Code FEs & Yes & Yes & Yes & Yes & Yes \\
\hline Year*Month FEs & Yes & Yes & Yes & Yes & Yes \\
\hline Day-of-week FEs & Yes & Yes & Yes & Yes & Yes \\
\hline Hour-of-day FEs & Yes & Yes & Yes & Yes & Yes \\
\hline Observations & $1,027,770$ & $1,027,770$ & $1,027,770$ & $1,027,770$ & $1,027,770$ \\
\hline Zip Codes & 720 & 720 & 720 & 720 & 720 \\
\hline
\end{tabular}

Notes: The dependent variable is the number of minutes it takes for the fire department to arrive on the scene after they receive the alarm (Response Time) for all emergency calls. Traffic D $i$ refers to the $i^{\text {th }}$ zip code-specific decile of deviations from free-flow. The columns add the total number of incidents within either a zip code or a fire department in a given hour on a given date. Cluster-robust standard errors clustered at the zip code level are in parentheses. ${ }^{*}$ $p<0.10,{ }^{* *} p<0.05,{ }^{* * *} p<0.01$

\subsection{Property damages and estimates for aggregate costs}

In order to assess the economic impact of traffic congestion on increased response times, we analyze the effect of traffic on property damages from fires. Table 12 presents the regression results of traffic on damages where the dependent variable is the natural log of the dollar value of property damages. These regressions only utilize fires as opposed to other emergencies. ${ }^{22}$ We examine the impact in both urban and non-urban areas. Column (1) presents our base specification for the whole sample; traffic in the 10th decile increases fire damages by roughly

\footnotetext{
${ }^{22}$ These regressions drop all observations where the damage or the value of property is missing.
} 
$9 \%$, and traffic in the 9 th decile has essentially zero effect. Columns (2) and (3) subset the sample by non-urban and urban zip codes; there is no significant effect in urban zip code and a $23 \%$ increase in damages for extreme traffic in non-urban zip codes. In the interaction model (column (4)) the difference in damages between urban and non-urban areas is not statistically significant. Non-urban areas may have larger damages from severe traffic for two reasons. First, response times in these areas are longer on average and fires display an exponential burn rate. Second, since our deciles are created from the whole sample, traffic above the tenth decile occurs less frequently in non-urban zip codes. Therefore, these events may be unexpected and fire departments may be less prepared to adapt to extreme traffic.

We also attempt to estimate the effect of response times on damages using traffic as an instrument. This would provide an estimate of the value of time for fire departments responding to a fire. A naive regression of damages on response times may confound the fact that dispatchers may prioritize fires that are expected to be very costly. We present the results in Table A.11 in the Appendix. The results are not precise but do suggest a large effect of an additional minute on the scene. An additional minute increases damages by 15$20 \%$. One reason why the results are noisy is that we lose many observations when focusing on fires that have valid damage data. The majority of incidents in our dataset are actually emergency medical services. ${ }^{23}$ The results are consistent with literature documenting an exponential burn rate where increases in response times can vastly increase fire damages $(\mathrm{Lu}$ et al., 2014).

From the property damage estimates, we generate back of the envelope calculations for the aggregate economic effect of traffic on emergency response services. First, we examine the effect of traffic on the dollar value of damages from fires. This does not include any injuries or deaths, nor does it include the effect of reduced response times on other types of emergencies. Since damages are only affected by the 10th traffic decile we scale the effects by average damages from fires and the annual number fires that occur in the 10th traffic decile. This results in $\$ 3.3$ million dollar in fire damages per year. ${ }^{24}$ There are several reasons

\footnotetext{
${ }^{23}$ We acknowledge that the sample used to estimate damage results is different than the primary estimation sample. The response time is quite similar in our damage sample (6.4 compared to 6.2 for full sample), but the average delay is somewhat lower (4.6 vs. 5.4 for full sample).

${ }^{24}$ This is calculated by multiplying the marginal effect of damages $(10 \%)$ by the mean damage $(\$ 35,879)$ and scaling
} 
Table 12: The effect of traffic on property damages

\begin{tabular}{lcccc}
\hline \hline & $(1)$ & $(2)$ & $(3)$ & $(4)$ \\
& Full & Non-Urban & Urban & Full \\
\hline Traffic Decile 9 & -0.00617 & -0.0486 & -0.000296 & -0.0675 \\
& $(0.0337)$ & $(0.0813)$ & $(0.0347)$ & $(0.0846)$ \\
Traffic Decile 10 & $0.0961^{* *}$ & $0.258^{* *}$ & 0.0718 & $0.204^{* *}$ \\
& $(0.0472)$ & $(0.107)$ & $(0.0495)$ & $(0.101)$ \\
Traffic Decile 9*Urban & & & & 0.0782 \\
& & & & $(0.0942)$ \\
Traffic Decile 10*Urban & & & & -0.117 \\
& & & Yes & Yes \\
Zip Code FEs & Yes & Yes & Yes & Yes \\
Year*Month FEs & Yes & Yes & Yes & Yes \\
Day-of-week FEs & Yes & Yes & Yes & Yes \\
Hour-of-day FEs & Yes & 21,574 & 60,554 & 82,128 \\
Observations & 82,128 & 126 & 528 & 654 \\
Zip Codes & 654 & & \\
\hline \hline
\end{tabular}

Notes: The dependent variable is the natural log of the dollar value of damages from a fire. Traffic $\mathrm{D} i$ refers to the $i^{\text {th }}$ decile of deviations from free-flow. The first column presents the full sample, column (2) focuses on non-urban zip codes, column (3) restricts the sample to urban zip codes, and column (4) interacts traffic deciles with an urban dummy. Cluster-robust standard errors at the zip code level are in parentheses. ${ }^{*} p<0.10,{ }^{* *} p<0.05,{ }^{* * *} p<0.01$

why this is likely a severe underestimate. First, we are only counting fires that have traffic sensors in the zip code, which is roughly $47.5 \%$ of all fires in the NIFRS data. Second, the NIFRS data only includes $75 \%$ of fire incidents. Extrapolating to all urban fires in California increases the damages to $\$ 9$ million per year. Lastly, we only include fires that have nonmissing damage estimates, which is only $35 \%$ of all fires. If we assume that damage data is randomly missing and fires without damage data are the same as those with damage data the annual costs of extreme traffic are $\$ 26$ million. The annual damage from traffic on urban fires ranges between $\$ 3-26$ million in California, which is several orders of magnitude smaller than estimates of alternative traffic externalities such as the value of time lost.

In order to assess the costs from non-fire emergencies, we also evaluate the impact of increased response times due to traffic on EMS mortality rates. Wilde (2013) estimates that a one minute increase in EMS response times leads to a $1 \%$ increase in 90-day mortality rates. Our estimates show that traffic slows down emergency medical response response by roughly 5 and 8 seconds in the 9 th and 10 th deciles, respectively. ${ }^{25}$ Combining the by the number of fires in the 10 th traffic decile per year $(\approx 1000)$. The 10 th traffic decile represents an increase of 0.17 minutes in emergency response time.

${ }^{25}$ This is based on the coefficent estimates for the 9th and 10th deciles in the EMS sample found in column (3) of 
$1 \%$ marginal mortality effect with our estimates of traffic on response times implies that traffic is responsible for an additional 9 deaths per year due to slower EMS services by fire departments, assuming a base mortality rate of $6 \%$ found in Wilde (2013). Extrapolating to EMS services provided by all fire departments in California generates 26 additional annual deaths due to slower EMS response times. Using the U.S. Department of Transportation's Value of a Statistical Life of $\$ 9.6$ million traffic increases social costs by roughly $\$ 258$ million due to increased mortality from EMS services. ${ }^{26}$ Combining both fire damages and mortality damages from slower response times, we estimate that traffic leads to additional costs between $\$ 95-\$ 285$ million due to the slowing down emergency response vehicles from fire departments.

These are clearly rough approximations that require significant extrapolation and should primarily used to provide the general range of economic damages due to traffic slowing down first responders. These damages do not account for costs associated with police or paramedics when fire departments are not on the scene, although they are also likely to face increased response times due to traffic congestion. Overall the additional fire damages from traffic are quite small. However, the effect of traffic EMS services, including potential effects on ambulances that we do not observe, are substantial but still significantly less than the value of lost time and fuel costs.

\section{Conclusion}

This paper examines the relationship between traffic and emergency response times. We match traffic data at a fine spatial and temporal scale to incident report data from fire departments, using fire department data collected by the NFIRS and traffic data from the California Department of Transportation for 2008 to 2015. Our results show that traffic delays fire trucks responding to fires, providing emergency medical services, and responding to other emergencies. Traffic also increases the average monetary damage from a fire. The effect of traffic on response time is nonlinear, with most of the impact concentrated in the 9th and 10th deciles. We then investigate potential common congestion policies that might

\section{Table 2 .}

${ }^{26}$ Documentation of revised value of statistical life estimates for the Department of Transportation are provided at: https://www.transportation.gov/sites/dot.gov/files/docs $/ 2016 \% 20$ Revised $\% 20$ Value $\% 20$ of $\% 20$ a $\%$ 20Statistical\%20Life\%20Guidance.pdf. This is consistent with the upper range estimated by Kniesner et al. (2012). 
mitigate this problem. We find that HOV lanes partially mitigate the marginal effect of traffic on response time. Fire department resources also appear to play a role in response times as response times increase when fire departments need to respond to multiple incidents. Our results document an additional externality of traffic congestion and highlight the complementarity of two important public goods. In aggregate, the increased monetary damages from fires and emergency medical services due to traffic is approximately $\$ 95-\$ 285$ million per year in California. These costs do not account for increased response times for ambulances or police, and therefore should be considered a lower bound for the costs of traffic on emergency response services. The results document an additional benefit for reducing traffic. We do not account for costs of adaptive investments that fire departments undertake to cope with traffic congestion. New stations or trucks might need to be purchased in order to maintain adequate response times, further increasing the costs of traffic congestion on first responders. Lastly, the results highlight the importance of understanding linkages between public goods. Understanding these linkages is important for properly allocating scarce public resources. 


\section{References}

Adler, Martin W. and Jos N. van Ommeren, "Does public transit reduce car travel externalities? Quasi-natural experiments' evidence from transit strikes," Journal of Urban Economics, 2016, 92, 106-119.

Albouy, David, Peter Christensen, and Ignacio Sarmiento-Barbieri, "Unlocking amenities: Estimating public good complementarity," Journal of Public Economics, 2020, 182, 104110.

Anderson, Michael L, "Subways, strikes, and slowdowns: The impacts of public transit on traffic congestion," American Economic Review, 2014, 104 (9), 2763-96.

_ , "As the wind blows: The effects of long-term exposure to air pollution on mortality," Journal of the European Economic Association, 2019.

_, Fangwen Lu, Yiran Zhang, Jun Yang, and Ping Qin, "Superstitions, Street Traffic, and Subjective Well-Being," Journal of Public Economics, 2016, 142, 1-10.

Bauernschuster, Stefan, Timo Hener, and Helmut Rainer, "When labor disputes bring cities to a standstill: The impact of public transit strikes on traffic, accidents, air pollution, and health," American Economic Journal: Economic Policy, 2017, 9 (1), 1-37.

Beaudoin, Justin and C. Y.Cynthia Lin Lawell, "The effects of public transit supply on the demand for automobile travel," Journal of Environmental Economics and Management, 2018, $88,447-467$.

Beland, Louis-Philippe and Daniel Brent, "Traffic and Crime," Journal of Public Economics, 2018, 160, 96-116.

Bento, Antonio, Daniel Kaffine, Kevin Roth, and Matthew Zaragoza-Watkins, "The effects of regulation in the presence of multiple unpriced externalities: Evidence from the transportation sector," American Economic Journal: Economic Policy, 2014, 6 (3), 1-29.

Bento, Antonio M, Jonathan E Hughes, and Daniel Kaffine, "Carpooling and driver responses to fuel price changes: Evidence from traffic flows in Los Angeles," Journal of Urban Economics, 2013, 77, 41-56.

Blackman, Allen, Francisco Alpízar, Fredrik Carlsson, and Marisol Rivera Planter, "A contingent valuation approach to estimating regulatory costs: Mexico's day without driving program," Journal of the Association of Environmental and Resource Economists, 2018, 5 (3), 607-641.

Borger, Bruno De and Stef Proost, "Traffic externalities in cities: the economics of speed bumps, low emission zones and city bypasses," Journal of Urban Economics, 2013, 76, 53-70.

Burger, Nicholas E and Daniel T Kaffine, "Gas prices, traffic, and freeway speeds in Los Angeles," The Review of Economics and Statistics, 2009, 91 (3), 652-657.

Couture, Victor, Gilles Duranton, and Matthew A Turner, "Speed," Review of Economics and Statistics, 2018, 100 (4), 725-739.

Currie, Janet and Reed Walker, "Traffic Congestion and Infant Health: Evidence from EZPass," American Economic Journal: Applied Economics, 2011, 3 (1), 65-90.

Donovan, Geoffrey H, Patricia A Champ, and David T Butry, "Wildfire risk and housing 
prices: a case study from Colorado Springs," Land Economics, 2007, 83 (2), 217-233.

Duranton, Gilles and Matthew A Turner, "The Fundamental Law of Road Congestion: Evidence from US Cities," American Economic Review, 2011, 101 (6), 2616-2652.

Emberson, Jonathan, Kennedy R Lees, Patrick Lyden, Lisa Blackwell, Gregory Albers, Erich Bluhmki, Thomas Brott, Geoff Cohen, Stephen Davis, Geoffrey Donnan et al., "Effect of treatment delay, age, and stroke severity on the effects of intravenous thrombolysis with alteplase for acute ischaemic stroke: a meta-analysis of individual patient data from randomised trials," The Lancet, 2014, 384 (9958), 1929-1935.

Gee, Gilbert C and David T Takeuchi, "Traffic stress, vehicular burden and well-being: a multilevel analysis," Social Science \& Medicine, 2004, 59 (2), 405-414.

Gendron-Carrier, Nicolas, Marco Gonzalez-Navarro, Stefano Polloni, and Matthew A. Turner, "Subways and Urban Air Pollution," Working Paper 24183, National Bureau of Economic Research January 2018.

Gibson, Matthew and Maria Carnovale, "The effects of road pricing on driver behavior and air pollution," Journal of Urban Economics, 2015, 89, 62-73.

Gottholmseder, Georg, Klaus Nowotny, Gerald J Pruckner, and Engelbert Theurl, "Stress perception and commuting," Health Economics, 2009, 18 (5), 559-576.

Gross, Austin and A. Daniel Brent, "Dynamic Road Pricing and the Value of Time and Reliability," Journal of Regional Science, 2018, 58 (2), 330-349.

Hamilton, Timothy L. and Casey J. Wichman, "Bicycle infrastructure and traffic congestion: Evidence from DC's Capital Bikeshare," Journal of Environmental Economics and Management, $2018,87,72-93$.

Hennessy, Dwight A and David L Wiesenthal, "Traffic congestion, driver stress, and driver aggression," Aggressive Behavior, 1999, 25 (6), 409-423.

i Vidal, Jordi Blanes and Tom Kirchmaier, "The effect of police response time on crime clearance rates," The Review of Economic Studies, 2015.

Jena, Anupam B, N Clay Mann, Leia N Wedlund, and Andrew Olenski, "Delays in emergency care and mortality during major US marathons," New England Journal of Medicine, 2017, 376 (15), 1441-1450.

Kahneman, Daniel, Alan B Krueger, David A Schkade, Norbert Schwarz, and Arthur A Stone, "A survey method for characterizing daily life experience: The day reconstruction method," Science, 2004, 306 (5702), 1776-1780.

Kniesner, Thomas J, W Kip Viscusi, Christopher Woock, and James P Ziliak, "The value of a statistical life: Evidence from panel data," Review of Economics and Statistics, 2012, 94 (1), 74-87.

Knittel, Christopher R, Douglas L Miller, and Nicholas J Sanders, "Caution, drivers! Children present: Traffic, pollution, and infant health," Review of Economics and Statistics, 2016, 98 (2), 350-366.

Konishi, Hideo and Se il Mun, "Carpooling and congestion pricing: HOV and HOT lanes," 
Regional Science and Urban Economics, 2010, 40 (4), 173-186.

Künn-Nelen, Annemarie, "Does commuting affect health?," Health Economics, 2016, 25, 9841004.

Lalive, Rafael, Simon Luechinger, and Armin Schmutzler, "Does expanding regional train service reduce air pollution?," Journal of Environmental Economics and Management, 2018, 92, 744-764.

Larsen, Mary P, Mickey S Eisenberg, Richard O Cummins, and Alfred P Hallstrom, "Predicting survival from out-of-hospital cardiac arrest: a graphic model," Annals of emergency medicine, 1993, 22 (11), 1652-1658.

Li, Shanjun, Yanyan Liu, Avralt Od Purevjav, and Lin Yang, "Does subway expansion improve air quality?," Journal of Environmental Economics and Management, 2019, 96, 213-235.

Lu, Lu, Chen Peng, Jiping Zhu, Kohyu Satoh, Deyong Wang, and Yunlong Wang, "Correlation between fire attendance time and burned area based on fire statistical data of Japan and China," Fire Technology, 2014, 50 (4), 851-872.

McCoy, Shawn J and Randall P Walsh, "Wildfire risk, salience \& housing demand," Journal of Environmental Economics and Management, 2018, 91, 203-228.

Moeltner, Klaus, M-K Kim, E Zhu, and W Yang, "Wildfire smoke and health impacts: A closer look at fire attributes and their marginal effects," Journal of Environmental Economics and Management, 2013, 66 (3), 476-496.

Mueller, Julie M, Ryan E Lima, Abraham E Springer, and Erik Schiefer, "Using Matching Methods to Estimate Impacts of Wildfire and Postwildfire Flooding on House Prices," Water Resources Research, 2018, 54 (9), 6189-6201.

Newgard, Craig D, Robert H Schmicker, Jerris R Hedges, John P Trickett, Daniel P Davis, Eileen M Bulger, Tom P Aufderheide, Joseph P Minei, J Steven Hata, K Dean Gubler et al., "Emergency medical services intervals and survival in trauma: assessment of the "golden hour" in a North American prospective cohort," Annals of emergency medicine, 2010, 55 (3), 235-246.

Ossokina, Ioulia V and Gerard Verweij, "Urban traffic externalities: Quasi-experimental evidence from housing prices," Regional Science and Urban Economics, 2015, 55, 1-13.

Parkinson, Brian, "Anger on and off the road," British Journal of Psychology, 2001, 92 (3), 507-526.

Pell, Jill P, Jane M Sirel, Andrew K Marsden, Ian Ford, and Stuart M Cobbe, "Effect of reducing ambulance response times on deaths from out of hospital cardiac arrest: cohort study," British Medical Journal, 2001, 322 (7299), 1385-1388.

Roberts, Jennifer, Robert Hodgson, and Paul Dolan, "It's driving her mad": Gender differences in the effects of commuting on psychological health," Journal of Health Economics, 2011, 30 (5), 1064-1076.

Schrank, David, Bill Eisele, and Tim Lomax, "TTI's 2019 urban mobility report," 2019 urban mobility report. Texas A\&M Transportation Institute, Texas, USA, 2019. 
Small, Kenneth A., Clifford Winston, and Jia Yan, "Uncovering the Distribution of Motorists' Preferences for Travel Time and Reliability," Econometrica, 2005, 73 (4), 1367-1382.

Wilde, Elizabeth Ty, "Do emergency medical system response times matter for health outcomes?," Health economics, 2013, 22 (7), 790-806.

Wolff, Hendrik, "Value of time: Speeding behavior and gasoline prices," Journal of Environmental Economics and Management, 2014, 67 (1), 71-88.

Yang, Jun, Shuai Chen, Ping Qin, Fangwen Lu, and Antung A. Liu, "The effect of subway expansions on vehicle congestion: Evidence from Beijing," Journal of Environmental Economics and Management, 2018, 88, 114-133. 


\section{Appendix}

\section{A Calculating deviation from free-flow}

The primary traffic variable is a weighted average deviation from free-flow speeds for all monitoring stations in a zip code. We call this variable "delay", and there are several steps to construct it. First, we construct a measure of free-flow speed for each zip code. Free-flow speed is simply the average speed for each monitoring station in the middle of the night (00:00-01:59am).

$$
F F_{m z}=\frac{1}{N} \sum_{t \in\{00: 00-01: 59\}} \text { speed }_{m z t}
$$

where speed $_{m z t}$ is the speed at monitoring station $m$ in zip code $z$ during 5 -minute interval $t$. Next, for every monitoring station we calculate the difference from the actual speed during a given 5-minute interval and the free-flow speed.

$$
d e v_{m z t}=\operatorname{speed}_{m z t}-F F_{m z}
$$

This provides a deviation from free-flow for each monitoring station. Last, for every zip code in each 5-minute interval we calculate a weighted average of all the monitoring stations' deviations from free-flow.

$$
\operatorname{delay}_{z t}=\frac{1}{N_{m}} \sum_{m} \operatorname{dev}_{m z t} * \text { weight }_{m z t}
$$

The weights are generated by the relative occupancy of a station across all times within the zip code. Therefore, the expression for the weights is:

$$
\text { weight }_{m z t}=\frac{\sum_{t \in\left\{\text { Month }_{t}\right\}} \text { flow }_{m z t}}{\sum_{m} \sum_{t \in\left\{\text { Month }_{t}\right\}} \text { flow }_{m z t}}
$$

We recalculate these weights every month to allow for changing utilization patterns over time, so weight $_{m z t}$ is time varying over months but not within a given month. Occupancy is a measure of how many cars pass through a road, and this measure places more weight on monitoring stations that are more heavily utilized. It should be noted that traffic congestion decreases occupancy so if a station is heavily congested all the time it will likely have less occupancy and receive a smaller weight. We also calculate a simple average of deviations from free-flow without any weights. The correlation between the weighted and unweighted measures of traffic congestion is 0.73 . The correlation of the deciles of traffic congestion constructed from the weighted and unweighted measures of traffic congestion is 0.88 . Our primary measure of traffic delay (delayzt) measures a weighted average of deviations from free-flow for all monitoring stations in a given zip code during a given 5-minute interval.

\section{B Constructing traffic deciles}

Our traffic congestion variable, delayzt, varies across zip codes and across 5-minute intervals. Aggregating all zip codes and all time results in a panel of traffic congestion from 2008-2015 where the cross sectional unit is the zip code and the time series unit is the 5-minute interval. This dataset is over 573 million observations. From this dataset we construct several deciles. The first is the aggregate deciles, which is simply the decile that any given observation of delayzt falls. We also create aggregate deciles based on the unweighted version of delayz. Next, we also create zip 
code-specific deciles. These deciles are constructed within each zip code based on the time series variation within the zip code. Finally, we merge in the decile for a 5-minute interval immediately prior to a fire alarm to assign the decile to an incident.

We calculate the deciles prior to the merge to capture the distribution of traffic in the population. Calculating the deciles after the merge would capture the traffic distribution of the sample of fire incidents, which may not be representative of the overall traffic distribution. This is shown in the data in Table A.1 as the proportion of observations within each traffic decile is not equal to 0.1. Rather more incidents occur in areas and during times where traffic is worse. This is not surprising because traffic is worse in areas with more people and during times when people are awake and active. The zip code and time fixed effects should control for most of these factors.

Table A.1: The proportion of fire calls within each traffic decile

\begin{tabular}{lc}
\hline Deciles & Proportion \\
\hline 1 & 0.07 \\
2 & 0.09 \\
3 & 0.09 \\
4 & 0.09 \\
5 & 0.10 \\
6 & 0.11 \\
7 & 0.12 \\
8 & 0.11 \\
9 & 0.10 \\
10 & 0.12 \\
\hline
\end{tabular}

\section{Absolute vs. zip code-specific deciles}

There are valid rationales for using either absolute or zip code-specific (relative) deciles for estimating the effect of traffic on response time. Using absolute deciles makes the variable consistent across different zip codes. If the physical limits of traffic are the same across space this is the correct specification. For example, we expect that when traffic reaches a $25 \mathrm{mph}$ delay, that would have a similar impact in different zip codes - conditional on the zip code fixed effect. If zip code features, such as infrastructure, play an important role in response times than perhaps a relative measure of congestion is more appropriate. We believe there are merits to both specifications and the results are qualitatively similar regardless of the specification. It should also be noted that the two measures are highly correlated $(\rho=0.89)$. The main difference is that high deciles are more likely to occur in heavily congested areas using the absolute measure of deciles compared to the relative measure. 


\section{Models for traffic expectations}

We assume that fire departments form expectations about the traffic conditions for any given incident based on their recent experience with traffic. We use fixed effects to account for the baseline traffic knowledge for their location, hour-of-day, day-of-week, year-month. More precise estimate are generated by recent traffic deviation using a moving average model - fire departments expect fire today to be a function of fire in recent similar time periods. What constitutes a "similar time period" is unknown so we develop several models. First, we assume that expectations are formed by the most recent week of traffic at the same hour as shown below.

$$
\text { delay }_{z t}=\beta_{0}+\gamma \frac{1}{N_{W}} \sum_{d=-7, h \in\{H\}}^{d=-1} \text { delay }_{z t}+\beta_{Z}+\beta_{M Y}+\beta_{D}+\beta_{H}+\eta_{z t}
$$

The week-hour specification averages all observations of traffic delay that occurred in the same hour, $H$, as a given incident over the past seven days. This specification assumes that recent traffic patterns at a given time of day serves as the basis of fire departments' expectations. From equation A.5 we calculate both the predicted value of delay $\left(\widehat{\text { delay }_{z t}}\right)$ the residual delay $\left(\widehat{\eta_{z t}}\right)$. We call $\widehat{\text { delay }_{z t}}$ expected traffic and $\widehat{\eta_{z t}}$ unexpected traffic and calculate deciles from both of these variables. The top two deciles are then used as the covariates in the analysis of expected and unexpected traffic as shown in Tables 5 and A.8.

We also generate a moving average model using traffic in the same hour over the past month as shown below.

$$
\text { delay }_{z t}=\beta_{0}+\gamma \frac{1}{N_{W}} \sum_{d=-30, h \in\{H\}}^{d=-1} \text { delay }_{z t}+\beta_{Z}+\beta_{M Y}+\beta_{D}+\beta_{H}+\eta_{z t}
$$

We also relax the assumption that fire departments are making hour-by-hour predictions and rather simplify to the morning peak, evening peak, or off-peak periods. This leads to the following two specifications of the prediction equation.

$$
\begin{aligned}
& \text { delay }_{z t}=\beta_{0}+\gamma \frac{1}{N_{W}} \sum_{d=-7, p \in\{P\}}^{d=-1} \text { delay }_{z t}+\beta_{Z}+\beta_{M Y}+\beta_{D}+\beta_{H}+\eta_{z t} \\
& \text { delay }_{z t}=\beta_{0}+\gamma \frac{1}{N_{W}} \sum_{d=-30, p \in\{P\}}^{d=-1} \text { delay }_{z t}+\beta_{Z}+\beta_{M Y}+\beta_{D}+\beta_{H}+\eta_{z t}
\end{aligned}
$$

where $p \in\{A M, P M, O F F\}$ the moving average is restricted to all observations in the same peak period, $P$, as the incident. 


\section{Additional tables and figures}

Table A.2: Summary statistics for top and all deciles by city

\begin{tabular}{llrr}
\hline City & Decile & Average Delay & Std. Dev. Delay \\
\hline All & All & 5.4 & 8.5 \\
Los Angeles & All & 6.9 & 10.0 \\
Bay Area & All & 5.9 & 8.9 \\
San Diego & All & 5.1 & 8.1 \\
Sacramento & All & 4.9 & 6.9 \\
Other & All & 2.6 & 4.9 \\
Los Angeles & 9 & 9.2 & 1.7 \\
Bay Area & 9 & 9.1 & 1.7 \\
San Diego & 9 & 9.1 & 1.7 \\
Sacramento & 9 & 9.1 & 1.7 \\
Other & 9 & 8.9 & 1.6 \\
Los Angeles & 10 & 25.9 & 10.2 \\
Bay Area & 10 & 24.8 & 9.4 \\
San Diego & 10 & 26.3 & 10.8 \\
Sacramento & 10 & 22.2 & 8.4 \\
Other & 10 & 20.5 & 8.0 \\
\hline
\end{tabular}

Notes: The table presents average and standard deviation of delay in miles per hour by city for all deciles, as well as the top two deciles.

Table A.3: Summary statistics by decile

\begin{tabular}{lrr}
\hline Decile & Average Delay & Std. Dev. Delay \\
\hline 1 & -1.2 & 1.3 \\
2 & -0.1 & 0.9 \\
3 & 0.5 & 0.9 \\
4 & 1.2 & 1.1 \\
5 & 2.0 & 1.6 \\
6 & 3.1 & 2.4 \\
7 & 4.4 & 3.7 \\
8 & 6.2 & 5.1 \\
9 & 9.4 & 7.4 \\
10 & 20.1 & 12.3 \\
\hline
\end{tabular}

Notes: The table presents average and standard deviation of delay in miles per hour for each decile. The first decile is negative, indicating that there are faster average speeds than our definition of free-flow. Our definition of free-flow assumes that there is no traffic from midnight to $2 \mathrm{AM}$, but speeds may be faster at other times. 
Table A.4: The effect of traffic on response time

\begin{tabular}{lcccc}
\hline \hline & $(1)$ & $(2)$ & $(3)$ & $(4)$ \\
& All Observations & Fires & EMS & Emergency Calls \\
\hline Traffic D9 & $0.101^{* * *}$ & 0.0862 & $0.0784^{* * *}$ & $0.0957^{* * *}$ \\
& $(0.0333)$ & $(0.0722)$ & $(0.0229)$ & $(0.0313)$ \\
Traffic D10 & $0.120^{* * *}$ & 0.0373 & $0.0927^{* * *}$ & $0.117^{* * *}$ \\
& $(0.0393)$ & $(0.0826)$ & $(0.0311)$ & $(0.0390)$ \\
\hline FD Code FEs & Yes & Yes & Yes & Yes \\
Year*Month FEs & Yes & Yes & Yes & Yes \\
Day-of-week FEs & Yes & Yes & Yes & Yes \\
Hour-of-day FEs & Yes & Yes & Yes & Yes \\
Observations & $1,230,623$ & 248,603 & 652,746 & $1,027,731$ \\
FD Codes & 425 & 398 & 244 & 413 \\
\hline \hline
\end{tabular}

Notes: The dependent variable is the number of minutes it takes for the fire department to arrive on the scene after they receive the alarm (Response Time). Traffic D $i$ refers to the $i^{\text {th }}$ decile of deviations from free-flow. The columns denote subsets of the data for incidents representing fires, all emergency medical services (EMS), and all emergency calls. Emergency calls includes fires, EMS calls as well as incidents where the fire department is dispatched to address incidents involving overpressure rupture, explosion, overheating or hazardous conditions without fires. Fire department fixed effects are used in each columns. Cluster-robust standard errors at the zip code level are in parentheses. ${ }^{*} p<0.10,{ }^{* *} p<0.05,{ }^{* * *} p<0.01$ 
Table A.5: Heterogeneity in traffic on response time by demographics

\begin{tabular}{|c|c|c|c|c|c|c|}
\hline & $\begin{array}{c}(1) \\
\text { Base }\end{array}$ & $\begin{array}{c}(2) \\
\text { High Income }\end{array}$ & $\begin{array}{c}(3) \\
\text { Low Income }\end{array}$ & $\begin{array}{c}(4) \\
\text { High Non-White }\end{array}$ & $\begin{array}{c}(5) \\
\text { Low Non-White }\end{array}$ & $\begin{array}{c}(6) \\
\text { Interaction }\end{array}$ \\
\hline Traffic D9 & $\begin{array}{l}0.135^{* * *} \\
(0.0231)\end{array}$ & $\begin{array}{l}0.168^{* * *} \\
(0.0340)\end{array}$ & $\begin{array}{l}0.102^{* * *} \\
(0.0314)\end{array}$ & $\begin{array}{c}0.0830^{* * *} \\
(0.0269)\end{array}$ & $\begin{array}{l}0.171^{* * *} \\
(0.0386)\end{array}$ & $\begin{array}{l}0.155^{* * *} \\
(0.0514)\end{array}$ \\
\hline Traffic D10 & $\begin{array}{l}0.191^{* * *} \\
(0.0263)\end{array}$ & $\begin{array}{l}0.230^{* * *} \\
(0.0381)\end{array}$ & $\begin{array}{l}0.150^{* * *} \\
(0.0350)\end{array}$ & $\begin{array}{l}0.131^{* * *} \\
(0.0300)\end{array}$ & $\begin{array}{l}0.234^{* * *} \\
(0.0446)\end{array}$ & $\begin{array}{l}0.201^{* * *} \\
(0.0552)\end{array}$ \\
\hline Traffic D9*Hi Inc. & & & & & & $\begin{array}{c}0.0197 \\
(0.0477)\end{array}$ \\
\hline Traffic D10*Hi Inc. & & & & & & $\begin{array}{l}0.00551 \\
(0.0493)\end{array}$ \\
\hline Traffic D9*Hi Non-White & & & & & & $\begin{array}{l}-0.0521 \\
(0.0500)\end{array}$ \\
\hline Traffic D10*Hi Non-White & & & & & & $\begin{array}{l}-0.0236 \\
(0.0520)\end{array}$ \\
\hline Zip Code FEs & Yes & Yes & Yes & Yes & Yes & Yes \\
\hline Year*Month FEs & Yes & Yes & Yes & Yes & Yes & Yes \\
\hline Day-of-week FEs & Yes & Yes & Yes & Yes & Yes & Yes \\
\hline Hour-of-day FEs & Yes & Yes & Yes & Yes & Yes & Yes \\
\hline Observations & $1,027,770$ & 512,608 & 515,162 & 519,962 & 507,808 & $1,027,770$ \\
\hline Zip Codes & 720 & 426 & 294 & 357 & 363 & 720 \\
\hline
\end{tabular}

Notes: The dependent variable is the number of minutes it takes for the fire department to arrive on the scene after they receive the alarm (Response Time) for all emergency calls. Traffic D $i$ refers to the $i^{t h}$ decile of deviations from free-flow. The columns examine different subsets based on zip code level demographics. The High and Low Income/Non-White columns restrict the sample to zip codes with above and below the sample medians. Column (6) interacts traffic delays with indicators for above the sample median income and proportion non-white. Cluster-robust standard errors at the zip code level are in parentheses. ${ }^{*} p<0.10,{ }^{* *} p<0.05,{ }^{* * *} p<0.01$ 
Table A.6: Robustness to different specifications - with fire department fixed effects

\begin{tabular}{lcccccc}
\hline \hline & $(1)$ & $(2)$ & $(3)$ & $(4)$ & $(5)$ & $(6)$ \\
& Base & Date & Metro*Date & Zip*All & Zip*All & Zip*All \\
\hline Traffic D9 & $0.135^{* * *}$ & $0.0916^{* * *}$ & $0.0815^{* * *}$ & $0.111^{* * *}$ & $0.111^{* * *}$ & $0.111^{* * *}$ \\
& $(0.0231)$ & $(0.0210)$ & $(0.0203)$ & $(0.0195)$ & $(0.0252)$ & $(0.0188)$ \\
Traffic D10 & $0.191^{* * *}$ & $0.166^{* * *}$ & $0.154^{* * *}$ & $0.170^{* * *}$ & $0.170^{* * *}$ & $0.170^{* * *}$ \\
& $(0.0263)$ & $(0.0234)$ & $(0.0222)$ & $(0.0231)$ & $(0.0333)$ & $(0.0288)$ \\
\hline Zip Code FEs & Yes & Yes & Yes & No & No & No \\
Fire Dept. FEs & No & Yes & Yes & Yes & Yes & Yes \\
Year*Month FEs & Yes & No & No & No & No & No \\
Day-of-week FEs & Yes & Yes & Yes & No & No & No \\
Hour-of-day FEs & Yes & Yes & Yes & No & No & No \\
Date FEs & No & Yes & No & No & No & No \\
Metro*Date FEs & No & No & Yes & No & No & No \\
Zip*Year*Month FEs & No & No & No & Yes & Yes & Yes \\
Zip*Day-of-week FEs & No & No & No & Yes & Yes & Yes \\
Zip*Hour-of-day & No & No & No & Yes & Yes & Yes \\
SE Cluster & Zip & Zip & Zip & Zip & Zip \& Month & Zip \& Hour \\
Observations & $1,027,770$ & $1,027,721$ & $1,027,617$ & $1,021,434$ & $1,021,434$ & $1,021,434$ \\
Zip Codes & 720 & 719 & 719 & 635 & 635 & 635 \\
\hline \hline
\end{tabular}

Notes: The dependent variable is the number of minutes it takes for the fire department to arrive on the scene after they receive the alarm (Response Time). Traffic D $i$ refers to the $i^{\text {th }}$ decile of deviations from free-flow. The columns examine different levels of fixed effects and two way clustering of the standard errors. Cluster-robust standard errors at the level described in the bottom panel are in parentheses. ${ }^{*} p<0.10,{ }^{* *} p<0.05,{ }^{* * *} p<0.01$ 
Table A.7: The effect of traffic on response time - zip code-specific deciles

\begin{tabular}{lcccc}
\hline \hline & $\begin{array}{c}(1) \\
\end{array}$ & Fll Observations & $(3)$ & $(4)$ \\
& $0.0850^{* * *}$ & $0.171^{* * *}$ & $0.0399^{* * *}$ & $0.0863^{* * *}$ \\
Traffic D9 & $(0.0212)$ & $(0.0637)$ & $(0.0141)$ & $(0.0227)$ \\
Traffic D10 & $0.176^{* * *}$ & $0.219^{* * *}$ & $0.101^{* * *}$ & $0.176^{* * *}$ \\
& $(0.0249)$ & $(0.0774)$ & $(0.0155)$ & $(0.0267)$ \\
\hline Zip Code FEs & Yes & Yes & Yes & Yes \\
Year*Month FEs & Yes & Yes & Yes & Yes \\
Day-of-week FEs & Yes & Yes & Yes & Yes \\
Hour-of-day FEs & Yes & Yes & Yes & Yes \\
Observations & $1,230,652$ & 248,631 & 652,743 & $1,027,770$ \\
Zip Codes & 721 & 709 & 602 & 720 \\
\hline \hline
\end{tabular}

Notes: The dependent variable is the number of minutes it takes for the fire department to arrive on the scene after they receive the alarm (Response Time). Traffic D $i$ refers to the $i^{\text {th }}$ zip code-specific decile of deviations from free-flow. The columns denote subsets of the data for incidents representing fires, all emergency medical services (EMS), and all emergency calls. Emergency calls includes fires, EMS calls as well as incidents where the fire department is dispatched to address incidents involving over-pressure rupture, explosion, overheating or hazardous conditions without fires. Cluster-robust standard errors at the zip code level are in parentheses. ${ }^{*} p<0.10,{ }^{* *} p<0.05,{ }^{* * *} p<0.01$ 
Table A.8: Heterogeneity in traffic on response time by traffic expectations - zip code-specific deciles

\begin{tabular}{|c|c|c|c|c|}
\hline & \multicolumn{2}{|c|}{ Hour } & \multicolumn{2}{|c|}{ Peak } \\
\hline & $(1)$ & $(2)$ & $(3)$ & $(4)$ \\
\hline & Week & Month & Week & Month \\
\hline \multirow[t]{2}{*}{ Expected D9 } & -0.0165 & -0.0387 & -0.0221 & -0.00205 \\
\hline & $(0.0257)$ & $(0.0237)$ & $(0.0270)$ & $(0.0261)$ \\
\hline \multirow[t]{2}{*}{ Expected D10 } & 0.0439 & 0.0659 & 0.0453 & 0.0383 \\
\hline & $(0.0361)$ & $(0.0412)$ & $(0.0394)$ & $(0.0396)$ \\
\hline \multirow[t]{2}{*}{ Unexpected D9 } & $0.0501^{* * *}$ & $0.0619^{* * *}$ & $0.0926^{* * *}$ & $0.0555^{* * *}$ \\
\hline & $(0.0174)$ & $(0.0175)$ & $(0.0196)$ & $(0.0194)$ \\
\hline \multirow[t]{2}{*}{ Unexpected D10 } & $0.171^{* * *}$ & $0.165^{* * *}$ & $0.166^{* * *}$ & $0.162^{* * *}$ \\
\hline & $(0.0272)$ & $(0.0271)$ & $(0.0258)$ & $(0.0255)$ \\
\hline First Stage & .89 & .96 & .75 & .58 \\
\hline Zip Code FEs & Yes & Yes & Yes & Yes \\
\hline Year*Month FEs & Yes & Yes & Yes & Yes \\
\hline Day-of-week FEs & Yes & Yes & Yes & Yes \\
\hline Hour-of-day FEs & Yes & Yes & Yes & Yes \\
\hline Observations & $1,027,770$ & $1,027,770$ & $1,027,770$ & $1,027,770$ \\
\hline Zip Codes & 720 & 720 & 720 & 720 \\
\hline
\end{tabular}

Notes: The dependent variable is the number of minutes it takes for the fire department to arrive on the scene after they receive the alarm (Response Time) for all emergency calls. Residual and Prediction refer to the residuals and predicted values from a moving average regression with all fixed effects and recent delays. The columns show different specifications for the month average; either the previous week or month and using the same our or same peak period (AM, PM or Off-Peak). First Stage shows the coefficient on the moving average variable in the first stage regression - a perfect prediction will have a value of one. Both the residuals and predicted values are standardized. Cluster-robust standard errors at the zip code level are in parentheses. ${ }^{*} p<0.10,{ }^{* *} p<0.05,{ }^{* * *} p<0.01$ 
Table A.9: Robustness to different specifications - without weighting for occupancy

\begin{tabular}{lcccccc}
\hline \hline & $(1)$ & $(2)$ & $(3)$ & $(4)$ & $(5)$ & $(6)$ \\
& Base & Date & Metro*Date & Zip*All & Zip*All & Zip*All \\
\hline Traffic D9 & $0.0754^{* * *}$ & $0.0585^{* * *}$ & $0.0439^{* *}$ & $0.0825^{* * *}$ & $0.0825^{* * *}$ & $0.0825^{* * *}$ \\
& $(0.0228)$ & $(0.0223)$ & $(0.0212)$ & $(0.0174)$ & $(0.0193)$ & $(0.0188)$ \\
Traffic D10 & $0.172^{* * *}$ & $0.147^{* * *}$ & $0.126^{* * *}$ & $0.147^{* * *}$ & $0.147^{* * *}$ & $0.147^{* * *}$ \\
& $(0.0280)$ & $(0.0275)$ & $(0.0266)$ & $(0.0269)$ & $(0.0320)$ & $(0.0277)$ \\
\hline Zip Code FEs & Yes & Yes & Yes & No & No & No \\
Year*Month FEs & Yes & No & No & No & No & No \\
Day-of-week FEs & Yes & Yes & Yes & No & No & No \\
Hour-of-day FEs & Yes & Yes & Yes & No & No & No \\
Date FEs & No & Yes & No & No & No & No \\
Metro*Date FEs & No & No & Yes & No & No & No \\
Zip*Year*Month FEs & No & No & No & Yes & Yes & Yes \\
Zip*Day-of-week FEs & No & No & No & Yes & Yes & Yes \\
Zip*Hour-of-day & No & No & No & Yes & Yes & Yes \\
SE Cluster & Zip & Zip & Zip & Zip & Zip \& Month & Zip \& Hour \\
Observations & $1,027,770$ & $1,027,764$ & $1,027,659$ & $1,021,476$ & $1,021,476$ & $1,021,476$ \\
Zip Codes & 720 & 720 & 720 & 635 & 635 & 635 \\
\hline \hline
\end{tabular}

Notes: The dependent variable is the number of minutes it takes for the fire department to arrive on the scene after they receive the alarm (Response Time). Traffic D $i$ refers to the $i^{t h}$ decile of deviations from free-flow. The columns examine different levels of fixed effects and two way clustering of the standard errors. Cluster-robust standard errors clustered at the level described in the bottom panel are in parentheses. ${ }^{*} p<0.10,{ }^{* *} p<0.05,{ }^{* * *} p<0.01$ 
Table A.10: Robustness to different specifications - average traffic

\begin{tabular}{lcccccc}
\hline \hline & $(1)$ & $(2)$ & $(3)$ & $(4)$ & $(5)$ & $(6)$ \\
& Base & Date & Metro*Date & Zip*All & Zip*All & Zip*All \\
\hline Lag Delay & $0.0639^{* * *}$ & $0.0537^{* * *}$ & $0.0475^{* * *}$ & $0.0562^{* * *}$ & $0.0562^{* * *}$ & $0.0562^{* * *}$ \\
& $(0.00937)$ & $(0.00903)$ & $(0.00871)$ & $(0.00887)$ & $(0.0117)$ & $(0.00985)$ \\
\hline Zip Code FEs & Yes & Yes & Yes & No & No & No \\
Year*Month FEs & Yes & No & No & No & No & No \\
Day-of-week FEs & Yes & Yes & Yes & No & No & No \\
Hour-of-day FEs & Yes & Yes & Yes & No & No & No \\
Date FEs & No & Yes & No & No & No & No \\
Metro*Date FEs & No & No & Yes & No & No & No \\
Zip*Year*Month FEs & No & No & No & Yes & Yes & Yes \\
Zip*Day-of-week FEs & No & No & No & Yes & Yes & Yes \\
Zip*Hour-of-day & No & No & No & Yes & Yes & Yes \\
SE Cluster & Zip & Zip & Zip & Zip & Zip \& Month & Zip \& Hour \\
Observations & $1,027,770$ & $1,027,764$ & $1,027,659$ & $1,021,476$ & $1,021,476$ & $1,021,476$ \\
Zip Codes & 720 & 720 & 720 & 635 & 635 & 635 \\
\hline \hline
\end{tabular}

Notes: The dependent variable is the number of minutes it takes for the fire department to arrive on the scene after they receive the alarm (Response Time). Lag Delay is the standardized ( $\mu=0$ and $\sigma=1$ ) deviation from free-flow in miles per hour. The columns examine different levels of fixed effects and two way clustering of the standard errors. Cluster-robust standard errors clustered at the level described in the bottom panel are in parentheses. ${ }^{*} p<0.10,{ }^{* *} p<0.05,{ }^{* * *} p<0.01$ 
Table A.11: The effect of response time on damages

\begin{tabular}{lcccc}
\hline \hline & $(1)$ & $(2)$ & $(3)$ & $(4)$ \\
& Full & Non-Urban & Urban & Full \\
\hline Response Time & 0.160 & 0.233 & 0.204 & 0.191 \\
& $(0.163)$ & $(0.157)$ & $(0.192)$ & $(0.242)$ \\
Response Time*Urban & & & & -0.0872 \\
& & & & $(0.524)$ \\
\hline F-stat & 1.73 & 0.75 & 1.51 & 0.48 \\
Zip Code FEs & Yes & Yes & Yes & Yes \\
Year*Month FEs & Yes & Yes & Yes & Yes \\
Day-of-week FEs & Yes & Yes & Yes & Yes \\
Hour-of-day FEs & Yes & Yes & Yes & Yes \\
Observations & 82,128 & 21,574 & 60,554 & 82,128 \\
Zip Codes & 654 & 126 & 528 & 654 \\
\hline \hline
\end{tabular}

Notes: The dependent variable is the natural log of the dollar value of damages from a fire. Response time is instrumented with the top three deciles of deviations from free-flow. Column (1) presents the base specification, column (2) drops response times over the 99th percentile, column (3) drops losses greater than $\$ 1$ million, and column (4) drops both sets of outliers. Cluster-robust standard errors clustered at the zip code level are in parentheses. ${ }^{*} p<0.10,{ }^{* *} p<0.05,{ }^{* * *} p<0.01$ 
Figure A.1: Effect of Deciles of Traffic on Response Time by Traffic Conditions

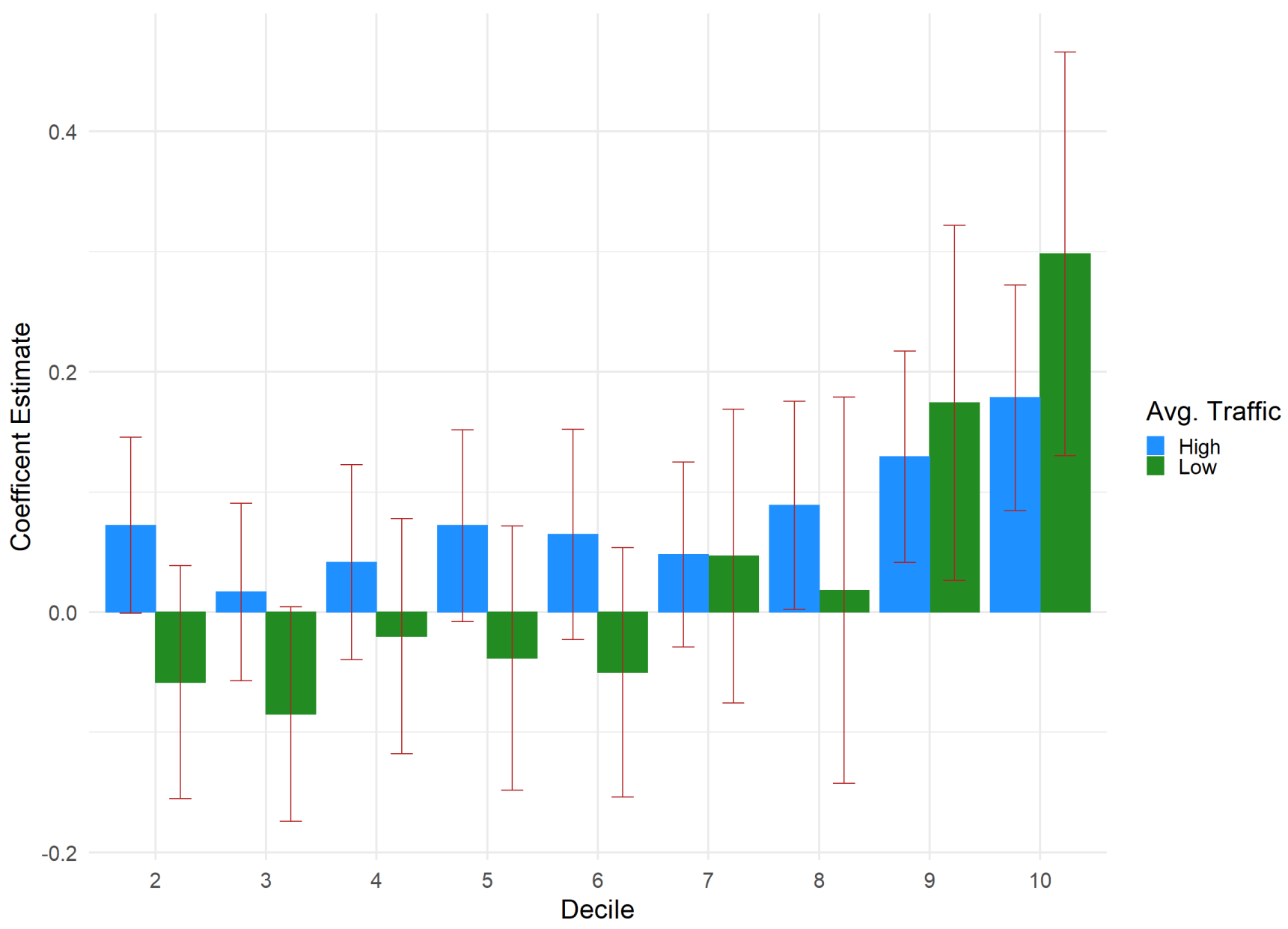

Notes: The figure plots the coefficient for indicators variables for deciles of traffic congestion from regressions where the dependent variable is response time (in minutes). The results are from two regressions, the High Traffic and Low Traffic regressions limit the sample to zip codes with average delays above and below the median average delay. The first decile is omitted to prevent perfect multicollinearity. The regressions includes zip code, year-by-month, day-of-week, and hour-of-day fixed effects. The $95 \%$ error bars are generated from cluster-robust standard errors at the zip code level. 
Figure A.2: The effect of deciles of traffic on response time by zip code-specific and aggregate deciles

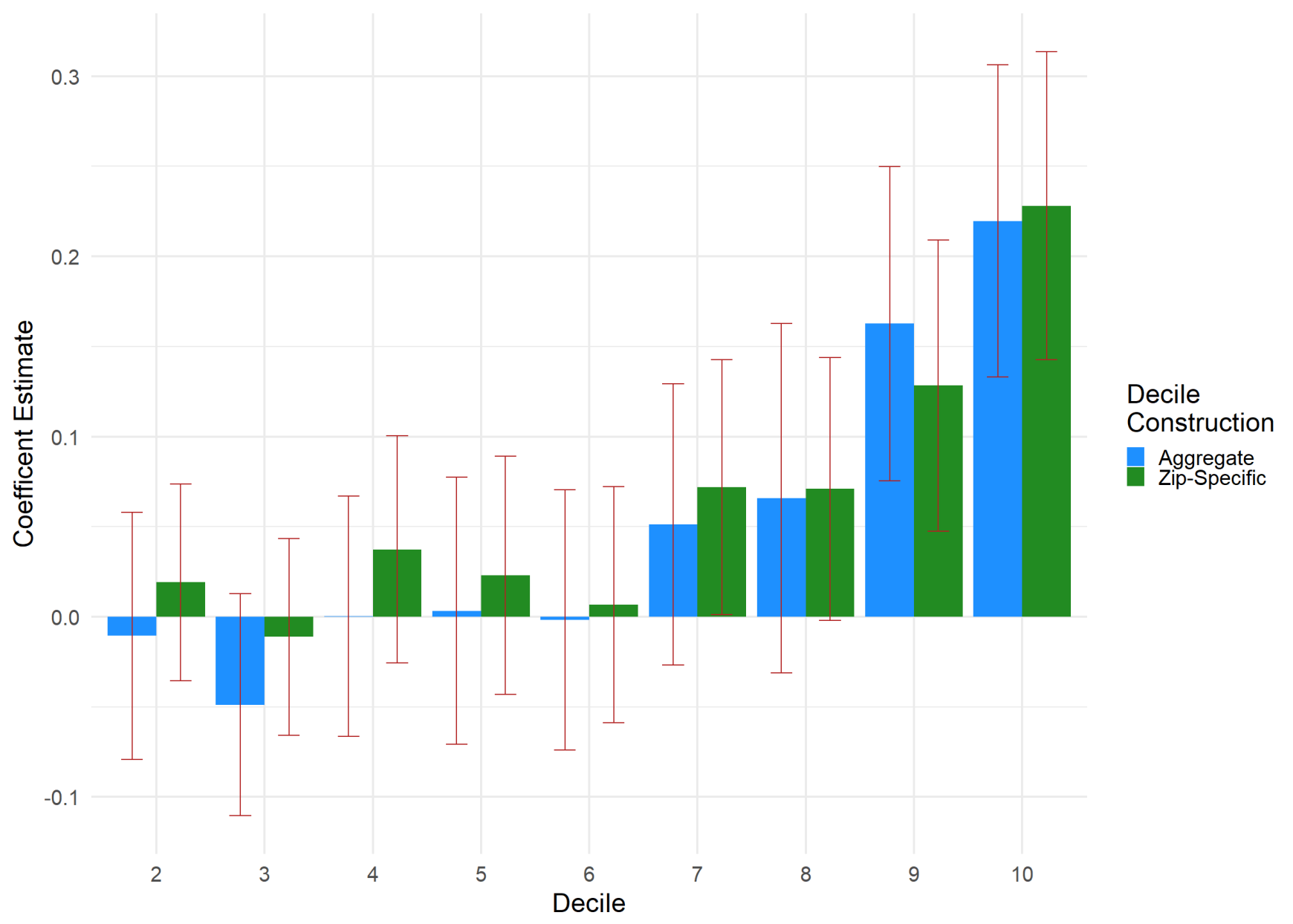

Notes: The figure plots the coefficient for indicators variables for deciles of traffic congestion from regressions where the dependent variable is response time (in minutes). The results are from two regressions. It shows coefficients for deciles created using all zip codes (called Aggregate) and zip code-specific deciles (called Zip-Specific). The regressions includes zip code, year-by-month, day-of-week, and hour-of-day fixed effects. The $95 \%$ error bars are generated from cluster-robust standard errors at the zip code level. 
Figure A.3: Spatial distribution of fire stations in Los Angeles County

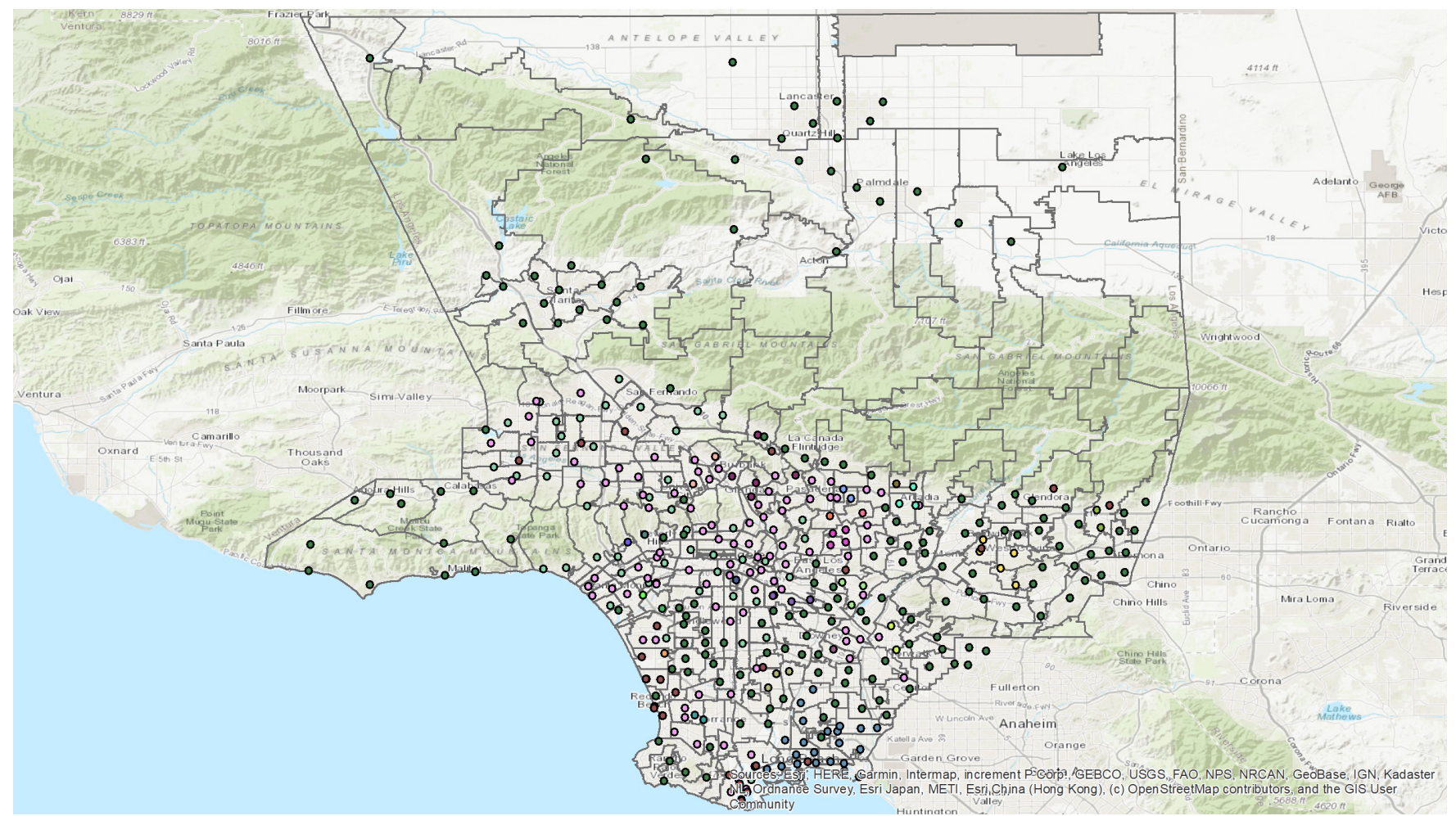

Notes: The map shows the location of fire stations in LA County. The different colors represent different fire departments. The dark outlines designate zip code boundaries. 